\title{
The Effect of using Repetitively Pulsed Laser Radiation in Selective Laser Melting when Creating a Metal Matrix Composite Ti-6Al-4V - B4C.
}

\section{Alexander Golyshev ( $\sim$ alexgol@itam.nsc.ru )}

Institut teoreticeskoj i prikladnoj mehaniki imeni SA Khristianovicha SO RAN https://orcid.org/00000002-4243-0602

\section{Alexander Malikov}

Institut teoreticeskoj i prikladnoj mehaniki imeni SA Khristianovicha SO RAN

\section{Anatoliy Orishich}

Institut teoreticeskoj i prikladnoj mehaniki imeni SA Khristianovicha SO RAN

\section{Mikhail Gulov}

Institut teoreticeskoj i prikladnoj mehaniki imeni SA Khristianovicha SO RAN

\begin{abstract}
Alexei Ancharov
Institute of Solid State Chemistry and Mechanochemistry Siberian Branch Russian Academy of Sciences
\end{abstract}

\section{Research Article}

Keywords: selective laser melting, repetitively pulsed radiation, cermet, microstructure, wear resistance

Posted Date: June 14th, 2021

DOl: https://doi.org/10.21203/rs.3.rs-579547/v1

License: (9) (1) This work is licensed under a Creative Commons Attribution 4.0 International License. Read Full License

Version of Record: A version of this preprint was published at The International Journal of Advanced Manufacturing Technology on August 13th, 2021. See the published version at https://doi.org/10.1007/s00170-021-07842-5. 


\section{Abstract}

A metal-matrix composite based on Ti-6Al-4V $-\mathrm{B}_{4} \mathrm{C}$ with $\mathrm{TiB}, \mathrm{TiB}_{2}$ and $\mathrm{TiC}$ inclusions was successfully obtained as a result of in-situ synthesis using repetitively pulsed laser radiation. For the first time, the phase composition of the obtained metal-matrix composite was studied using synchrotron radiation. A comparison of the effect of using continuous and pulsed-periodic radiation in selective laser melting on the microstructure and mechanical properties of coatings was made. The use of repetitively pulsed radiation made it possible to form more uniform structures and to improve the mechanical properties of metal-matrix coatings in comparison with the continuous mode of exposure. It has been established that the use of repetitively pulsed radiation and the formation of $\mathrm{TiB}_{2}, \mathrm{TiB}, \mathrm{TiC}$ phases made it possible to increase the wear resistance of the formed composite by a factor of 6 in comparison with the Ti-6Al-4V metal coating.

\section{Introduction}

Additive technologies (AT) of parts manufacturing are entering the industrial level today. The most widely used and versatile AT for the production of 3D parts is selective laser melting (SLM) [1].

To improve the characteristics of the formed products under industrial conditions, several types of metalmatrix composite (MMC) materials have been developed, including $\mathrm{MMC}$ based on $\mathrm{Al}, \mathrm{Ti}, \mathrm{Fe}, \mathrm{Cu}, \mathrm{Mg}$, and $\mathrm{Ni}$, reinforced with either fibers or particles [2-6].

Titanium is a very promising material, which is characterized by the highest strength-to-weight ratio among metals, along with high corrosion resistance [7-11]. Sintered composites based on $\mathrm{B}_{4} \mathrm{C}, \mathrm{TiC}, \mathrm{TiB}$, $\mathrm{TiB}_{2}$ ceramics and titanium metal binder have demonstrated good performance due to their high compatibility, high melting point, extreme hardness, excellent wear resistance and corrosion resistance, combined with excellent fracture toughness[12-17]. These composites are mainly obtained by hot pressing or casting. One of the main problems in the production of metal-matrix composites is to ensure the physicochemical compatibility of the matrix and the reinforcing phase.

Currently, there is a need to obtain MMC coatings on structural materials. One of the most promising methods of creating a composition is the use of high-energy sources. In this case, both laser radiation [18-24] and an electric discharge arc [25-28] were used as energy sources.

The creation of $\mathrm{MMC}$ is possible by ex-situ synthesis (using $\mathrm{TiC}$ and $\mathrm{TiB}_{2}$ powders) [29-32] or in-situ synthesis (using $\mathrm{Ti}$ and $\mathrm{B}_{4} \mathrm{C}$ or another precursor)[18-23,33]. It should be noted that a large number of works are devoted to the development of surface hardening methods by creating a metal-ceramic coating using the in-situ method for a $\mathrm{TiC}^{-} \mathrm{TiB}_{2}$ mixture. The $\mathrm{MMC}$ with $\mathrm{TiC}^{-} \mathrm{TiB}_{2}$ ceramics, prepared by in-situ synthesis, provides uniform distribution of reinforcing particles, along with excellent interfacial bonding between particles, which increases the stability and fracture toughness of the composite compared to the composite prepared by ex-situ synthesis [23]. The microstructure, phase composition and mechanical 
characteristics of the deposited material were investigated. It has been shown that the coating has 3 to 4 times the hardness of the substrate.

Consequently, the development of the method of in-situ synthesis of $\mathrm{TiC}^{-\mathrm{TiB}_{2}}$ i.e. the use of $\mathrm{Ti}$ and $\mathrm{B}_{4} \mathrm{C}$ starting powders is a promising direction in the creation of a metal-ceramic composite.

In recent works $[23,24]$ during in-situ synthesis using $\mathrm{Ti}$ and $\mathrm{B}_{4} \mathrm{C}$ powders and continuous laser radiation, the formation of the phase composition was investigated and it was shown that crystallization of TiB begins first and TiC crystallization goes after. Xia et al.[24] investigated the effect of laser radiation power on the coating structure; as a result, an increase in the size of crystals and a decrease in microhardness with increasing power was shown.

However, a very small number of studies are devoted to the study of the effect of changing the ratio of the initial concentration of a mixture of Ti powders and a composite coating on the quality of SLM deposited layer $[7,28]$. The formation of a deposited layer using an electric discharge arc (TIG) at high weight concentrations ( $\mathrm{Ti}-\mathrm{B}_{4} \mathrm{C}=5: 1,3: 1$ and 3: 2) was studied [28]. It is shown that $\mathrm{TiC}, \mathrm{TiB}_{2}, \mathrm{TiB}$ and $\mathrm{TiAl}_{3}$ are the main constituents existing in the coating. The uniformity of the resulting coating is much higher when using a $5 \mathrm{Ti}-\mathrm{B}_{4} \mathrm{C}$ powder blend compared to a coating made with a relatively higher percentage of $\mathrm{B}_{4} \mathrm{C}$, i.e. $3 \mathrm{Ti}-\mathrm{B}_{4} \mathrm{C}$ (stoichiometric ratio) and $3 \mathrm{Ti}-2 \mathrm{~B}_{4} \mathrm{C}$. At the same time, in all modes, pores and microcracks are observed, the number of which depends on the arc current.

The transition to multilayer coatings fundamentally changes the character of crack propagation, which is scarcely studied, especially considering the influence of the initial concentration of $\mathrm{B}_{4} \mathrm{C}$ and the endothermic nature of the reaction of boron with titanium on this process. In addition, a number of AT problems associated with the quality of the metal obtained by additive manufacturing remain unresolved. For example, the rough dendritic structure and texture of products made of titanium alloys can significantly reduce the level of mechanical properties (yield strength, tensile strength, fracture toughness, impact toughness, abrasive wear resistance, low-cycle and high-cycle fatigue life).

One of the methods to improve the characteristics of metal matrix composite materials (MMC) obtained with selective laser melting (SLM) is through the use of vibration. There are various methods of introducing of vibrations into the welding zone, such as, for example, electric arc vibrations [34,35], direct introduction of vibrations into the material through a waveguide [36].

These methods make it possible to improve weldability without the need for heat treatment, which leads to a reduction of the technological cycle and a decrease in the cost and time for the production of products. The overwhelming majority of works (for example, [36-38]) are aimed at using mechanical vibrations in arc welding in order to improve the structure and properties of welded joints.

Thus, the implementation of external periodic mechanical impact and pulse periodic input of heat showed the advantage of methods of pulse-arc welding on the formation of the structure and properties of the weld [39]. Various aspects of the positive influence of repetitively pulsed welding on the weld 
structure are investigated [40]. The source of oscillations was a modulated current, an alternating electromagnetic field, or a pulsed generation of laser radiation. Reaching of resonance conditions - the coincidence of the frequencies of the external influence and the natural frequency of crystallization, can lead to the dominance of certain physicochemical processes that simultaneously occur at a given time and affect structural changes. The studies $[41,42]$ describe the production of a homogeneous structure of composite protective coatings based on ceramic and intermetallic materials using vibration and modification of the structure during melting in combination with vibration.

A separate cycle of research, both theoretical and experimental, is devoted to the study of the behavior of a liquid in the presence of vibrational oscillations. Even in the first works it was shown that highfrequency vibrations lead to the generation of an averaged flow in a viscous boundary layer near the body surface [43]. In [44], the effect of low-amplitude vibrations on Marangoni convection was studied. During the experiments, the critical temperature differences and the role of vibrations in changing states in a liquid were determined. The results showed that, under vibration exposure, vibration movement occurs for a smaller critical temperature difference, which is associated with the influence of vibrations on the shape of the free surface. The results presented in [45] show that in the presence of vibrations, the positions of the vortex centers in the radial and axial directions periodically deviate from their equilibrium positions. The speed of the surface movement without lateral vibrations is greater than with vibrations, which means that lateral vibrations suppress the surface flow.

Thus, the changes occurring in the melt, in the structure of a specific zone of the weld during the crystallization process under the influence of vibration can be both positive and negative, it depends on many characteristics of the vibration impact. There is a need to determine the permissible ranges of technological parameters that make it possible to control the shape of the melt, the direction and intensity of its convective movement, the influence of chemical reactions and the role of additional energy as a result of an exothermic reaction, the free surface of the melt in the melting zone, the shape of the crystallization front and the speed of its movement.

It stimulates the research of new methods of selective laser melting, which will improve the structure and mechanical characteristics of the obtained cermet material. This, in turn, will provide the technological basis for the additive production of aircraft parts with the specified characteristics of the material obtained by layer-by-layer laser-melting technology.

In this work, composite multilayer samples prepared by selective laser melting (SLM) using a pre-stacked powder mixture based on $\mathrm{Ti}$ and $\mathrm{B}_{4} \mathrm{C}$ at different mass ratios and creating a $\mathrm{TiB}-\mathrm{TiC}-\mathrm{TiB}_{2}$ mixture using in-situ synthesis were studied. For the first time in the SLM method, a $\mathrm{CO}_{2}$-laser operating in a repetitively pulsed mode with frequencies of $50-160 \mathrm{kHz}$ with an average power of up to $2 \mathrm{~kW}$ was used and the influence of the dynamic and thermal disturbances generated by it on the characteristics and formation of the deposited layer was investigated. The main task was to create a composite 3D material with minimal number of defects and to investigate the influence of the composition of the initial powder on the microstructure, microhardness and level of abrasive wear. 


\section{Materials And Experimental Technique}

To obtain composites based on a metal matrix, a cermet powder mixture was used in this work. It included a fragment-shaped boron carbide $\mathrm{B}_{4} \mathrm{C}$ powder (Fig. 1a), the average size of which was $\mathrm{d}=$ $40 \mu \mathrm{m}$, and a spherical titanium alloy Ti-6Al-4V powder (Fig.1.b) with a particle size from $10 \mu \mathrm{m}$ to $45 \mu \mathrm{m}$.

The powders were mixed in a Venus FTLMV-02 V-shaped mixer with different ratios for one hour until a homogeneous powder mixture was formed. The concentration of $\mathrm{B}_{4} \mathrm{C}$ ceramics in the initial powder mixture ranged from 2 to $20 \mathrm{wt} \%$.

Using the selective laser melting (SLM) method, the powder mixture was deposited onto a substrate in the form of a plate made of titanium alloy Ti-6.5Al-1.8Zr-1.5Mo with dimensions of $50 \times 50 \times 5 \mathrm{~mm}$.

The ALTC "Siberia" based on a gas-discharge $\mathrm{CO}_{2}$ laser with repetitively pulsed radiation was used as a source of laser radiation. This complex was developed at the Khristianovich Institute of Theoretical and Applied Mechanics SB RAS [46]. The oscillogram of a single laser pulse is shown in Fig. 2.

Laser radiation with a wavelength of $10.6 \mu \mathrm{m}$ was focused using a ZnSe lens with a focal length of 254 $\mathrm{mm}$ deep into the material, onto the surface and above the material. The selective laser melting was carried out in a protective atmosphere of helium supplied through a nozzle. The thickness of the applied layer of the powder mixture was $250 \mu \mathrm{m}$. Optimization of the parameters of laser beam irradiation for repetitively pulsed radiation (RPR) was carried out in the same way as for continuous radiation [47]. The parameters varied such as the radiation power (from $500 \mathrm{~W}$ to $1500 \mathrm{~W}$ ), the position of the focus relative to the powder layer ( $\mathrm{f}$ varied from $-30 \mathrm{~mm}$ to $+30 \mathrm{~mm}$ with a step of $5 \mathrm{~mm}$ ), the scanning speed (from 0.5 $\mathrm{m} / \mathrm{min}$ to $1,5 \mathrm{~m} / \mathrm{min})$, pulse frequency $(20 \mathrm{kHz}$ to $100 \mathrm{kHz})$.

The formed composites were studied using an Olympus LEXT OLS 3000 (OM) optical confocal microscope. The study of the microstructure was carried out using a Zeiss EVO MA 15 scanning electron microscope (SEM) equipped with a backscattered electron detector for determining the phase composition and a secondary electron detector for analyzing the surface microrelief.

Microhardness measurements were carried out on a Wilson Hardness Group Tukon1102 microhardness tester using the Vickers method at a load of $300 \mathrm{~g}$.

The phase composition of the surface of the samples was carried out using X-ray diffraction (X-Ray). The diffraction patterns were recorded on a D8 Advance diffractometer using the characteristic radiation of the copper anode of the Cu-Ka X-ray tube $(\lambda=1.5406 \AA)$, a nickel filter for suppressing the reflection from $\mathrm{Cu}-\mathrm{K} \beta$ radiation, and a linear position-sensitive detector Lynx-Eye. The phase composition was decrypted using the Pdf4 database.

The X-ray diffraction in transmission mode was carried out using synchrotron radiation (SR) at the station of the 4th channel VEPP-3 located at the Institute of Nuclear Physics. G.I. Budker SB RAS, at the "Diffractometry in hard X-ray radiation" station [48]. A sample with dimensions of $4 \mathrm{~mm}$ by $4 \mathrm{~mm}$ and a 
thickness of $1 \mathrm{~mm}$ was studied over the entire height using SR with a wavelength of $0.3685 \AA$ in the Debye-Sherard geometry. The survey was carried out sequentially, starting from the upper layer, in the range from $0^{\circ}$ to $22^{\circ}$ with a step of $100 \mu \mathrm{m}$. The beam diameter was $100 \mu \mathrm{m}$.

Diffraction rings were recorded using a two-dimensional Mar345 detector. In these studies, the contribution to the diffraction pattern was made not only by the surface layers of the sample, but by the entire volume of the substance through which the radiation flux passes. The phase composition was studied using a beam of monochromatic synchrotron radiation with a cross section of $100 * 400 \mu \mathrm{m}$. The resulting diffraction rings are integrated over the radius and recalculated for $\lambda=1.5406 \AA$.

Wear resistance was evaluated using tests carried out by interaction of the test sample with abrasive paper (Fig. 4). The using of a spiral trajectory on abrasive paper ensures a stable wear process of the sample, because it provides a constant contact of the sample surface with new abrasive particles.

The tests were carried out at a load of $10 \mathrm{~N}$ for 30 minutes in air, with P80 abrasive paper (particle size of $200 \mu \mathrm{m}$ ), the rotation speed was $150 \mathrm{rpm}$. On average, three measurements were performed on each of the composites. The roughness of the working surface before testing was not more than Ra 2.5.

\section{Results Of Experiments And Discussion}

\subsection{Optimization of the laser exposure mode for a single track formation.}

It is necessary to optimize the parameters of the laser exposure of the powder mixture during the formation of single tracks to form a high-quality multilayer cermet structure. As a result, the same as for continuous radiation [49], the optimal parameters of laser exposure for repetitively pulsed radiation depend on the concentration of ceramics weakly and are as follows: $t=250 \mu \mathrm{m}, \mathrm{W}=1000 \mathrm{~W}, \mathrm{~V}=0.7 \mathrm{~m} /$ $\min , \mathrm{f}=-18 \mathrm{~mm}, \mathrm{~F}=60 \mathrm{kHz}$.

The arrays which consist of 6 tracks with a step of $1 \mathrm{~mm}$ between tracks were formed using this mode. These arrays consist of 8 deposited layers. Note that the position of the tracks in every next layer shifted relative to the previous layer by $\pm 0.5 \mathrm{~mm}$. To highlight the features of the formation of the deposited layer in a pulse-periodic mode, a control surfacing was carried out in a continuous mode of laser radiation with the same irradiation parameters.

\subsection{Microstructure of track array}

Figure 5 obtained by an optical microscope shows the cross-section structure of the polished samples, deposited in a pulsed-periodic mode with different initial concentrations of $\mathrm{B}_{4} \mathrm{C}$ ceramics. It can be seen that at a ceramic concentration of $10 \% \mathrm{wt}$. the deposited mass is homogeneous and does not have cracks, however, with an increase in concentration of ceramic to $15 \mathrm{wt}$. \%, transverse cracks are formed (same as for continuous radiation [49]). 
A comparative analysis of samples obtained using continuous and repetitively pulsed radiation (Fig. 6-7) has been carried out. Differences are observed in the macro (Fig. 6) and microstructure (Fig. 7) depending on the type of laser used.

Fig. 6 shows the typical structure of the polished samples deposited in pulse-periodic (Fig.6a) and continuous (Fig.6b) modes at a ceramic concentration of $10 \mathrm{wt} \%$. The photographs include the substrate boundary (Fig. 6b) and the deposited layer.

At the macroscale, for repetitively pulsed radiation, pores are practically not observed in the formed multilevel structures (Fig. 6a). In turn, in the coating obtained using continuous radiation and similar energy parameters, both large pores and micropores are observed (Fig. 6 b). As can be seen from the Fig. 5 and Fig. $6 a$, large ceramic particles, especially at a high initial concentration of $B_{4} C(\geq 10 \%)$, concentrate on the lateral edges of the tracks, forming a rather ordered structure of the arrangement of bunches in samples obtained with the pulse-periodic radiation. Moreover, taking into account the shift of $\pm 0.5 \mathrm{~mm}$ in the position of the tracks in every next layer relative to the previous, the bunches of particles are also shifted. When using continuous radiation, ceramic particles are localized at the lower boundary of the deposited layer (Fig. 6b). An important feature of the PPR application is the homogeneity of solid solution of the deposited layer at the macrolevel (Figs. 5 and 6a), while the use of a continuous radiation causes a large structural inhomogeneity (Fig. $6 \mathrm{~b}$ and [49]) of the solid solution.

At the micro scale, the differences in the structure of the deposited layer are also observed for two types of laser radiation. The EDX image of the cross-section structure of the polished samples obtained using pulse-periodic (a) and continuous radiation (b) at a ceramic concentration of $10 \mathrm{wt} \%$ is shown in Fig. 7.

Continuous radiation is characterized not only by a separate localization of large particles, but also by the formation of a separate layer where the dark needle-like structures - whiskers are located, i.e. there occurs a separation of the solid solution according to the microstructure and the content of certain phases.

When using PPR, a different picture is observed (see Fig. 7). In this case, the ceramic particles are surrounded by structures of secondary phases (whiskers and submicron particles) formed as a result of an exothermic reaction between boron carbide and titanium. In other words, we can say that when using repetitively pulsed radiation, a more homogeneous microstructure is observed (see Fig. 7 a).

However, after a more detailed analysis, it becomes clear that when using PPR, the structure of the deposited layer at the micron and submicron level becomes inhomogeneous, it contains a rich set of secondary phases of various sizes and different chemical compositions. Fig. 8 shows an EDX image of the microstructure of a Ti-Al-V $-\mathrm{B}_{4} \mathrm{C}$ sample with a 9: $1 \mathrm{wt} \%$ ratio in two different locations at the micron scale. The presented figures show the difference in the local structures of the deposited layer. Note that the image in Fig. 8 was obtained in the chemical contrast mode. One can see the presence of white and gray particles in a very wide range of sizes from submicron to tens of microns, in which heavy elements predominate. In this case these can be the $\mathrm{TiB}, \mathrm{TiB}_{2}$ and $\mathrm{TiC}$ phases. 
Typical results of studying the local distribution of carbides in the coating volume are shown in Fig. 9. When carrying out the averaged elemental analysis of the deposited zone containing secondary phases (Table. 1, spectrum 2), a sharp increase in the boron content is observed in comparison with the region, predominantly containing a metal matrix (Table. 1, spectrum 1). Dark particles in the form of whiskers (needle-like structures) (Table. 1spectrum 4) are a compound of boron and titanium ( $\left.\mathrm{TiB}_{2}\right)$.

Table 1. Chemical composition of the spectra shown in Fig.9

\begin{tabular}{|c|c|c|c|c|c|c|c|c|c|c|}
\hline \multirow[t]{3}{*}{ № spectrum } & \multicolumn{10}{|c|}{ Chemical element (\%) } \\
\hline & \multicolumn{2}{|l|}{ B } & \multicolumn{2}{|l|}{ C } & \multicolumn{2}{|l|}{ Al } & \multicolumn{2}{|l|}{$\mathrm{Ti}$} & \multicolumn{2}{|l|}{ v } \\
\hline & wt & at & wt & at & wt & at & wt & at & wt & at \\
\hline 1 & 1.47 & 5.63 & 2.14 & 7.39 & 5.69 & 8.73 & 87.16 & 75.37 & 3.54 & 2.88 \\
\hline 2 & 12.98 & 35.15 & 5.35 & 13.04 & 4.28 & 4.64 & 74.37 & 45.44 & 3.02 & 1.74 \\
\hline 3 & - & - & 7.65 & 12.08 & 7.65 & 12.08 & 85.32 & 75.92 & 4.77 & 3.99 \\
\hline 4 & 27.01 & 58.44 & 4.04 & 7.87 & 0.21 & 0.18 & 66.33 & 32.40 & 2.41 & 1.11 \\
\hline
\end{tabular}

\subsection{Phase composition of the track array}

X-ray diffraction analysis of the Ti-6Al-4V $-\mathrm{B}_{4} \mathrm{C}$ sample with a ratio of 9: $1 \mathrm{wt} \%$ was carried out. As a result, the presence of $\mathrm{a}-\mathrm{Ti}, \mathrm{V}_{2} \mathrm{C}, \mathrm{TiC}$ in the sample was shown (see Fig. 10). However, it should be noted that there is a high level of noise in the X-ray pattern, which makes it difficult to decipher the chemical compounds.

For a more accurate determination of phase compounds, a diffraction study was carried out using synchrotron radiation.

Figure 11 shows the diffraction patterns. As a result, the presence of a larger number of phase compounds in the deposited layer in comparison with reflection X-ray diffraction patterns is shown. In Fig. 11, it can be noted that the sample with cladded Ti-6Al-4V $-\mathrm{B}_{4} \mathrm{C}$ with a ratio of $9: 1 \%$ of the mass. includes $\mathrm{a}-\mathrm{Ti}, \mathrm{TiB}_{2}, \mathrm{TiB}, \mathrm{TiC}, \mathrm{V}_{2} \mathrm{C}, \mathrm{TiAl}_{3}$. It should be noted the homogeneity of the phase composition over the thickness of the deposited layer.

The most important result of these measurements is the comparable intensity of the diffraction maxima of the secondary phases $\mathrm{TiB}_{2}, \mathrm{TiB}, \mathrm{TiC}$ and the $\mathrm{a}-\mathrm{Ti}$ solid solution. This circumstance shows that most of the $\mathrm{Ti}$ is involved in the creation of ceramic crystals.

\subsection{The measurement of mechanical characteristics: microhardness and wear resistance of the resulting coatings}

For all the composites obtained, the microhardness was measured. 
Figure 12 shows the dependence of the average microhardness and the spread of values on the concentration of ceramics in the initial powder mixture for samples obtained using periodic and continuous radiation. Averaging was carried out over 10 measurements of microhardness at different points throughout the sample. It is seen that with an increase in the concentration of ceramics, the average microhardness increases. The spread of microhardness values in a continuous cut of laser radiation exceeds the spread of the PPR data.

The microstructure of the formed samples with a ceramic concentration of 2 and $4 \%$ wt. was observed, it appeared to be close to the original metal matrix (Ti-6Al-4V) and, as a result, the microhardness of such arrays at different points remains the same and is approximately $444.7 \mathrm{HV} 0.3$ and $472.9 \mathrm{HVO} 0.3$, respectively.

A different picture is observed for arrays with a ceramic concentration of $6 \% \mathrm{wt}$. and more. In this case, when using continuous laser radiation, a heterogeneous structure is formed with zones which have different microstructure (see, for example, Fig. 7) and, as a consequence, different mechanical characteristics, and the microhardness in different zones can vary several times, from $400 \mathrm{HV} 0.3$ up to 1400 HVO.3 (see fig. 13)

The microhardness of the $\mathrm{B}_{4} \mathrm{C}$ ceramic particle in the metal matrix of the sample is approximately 4200 HV0.3. The data presented show that the maximum microhardness is recorded in the presence of a heterogeneous structure, including small ceramic crystals of the $\mathrm{TiB}_{2}, \mathrm{TiB}$ phases, and their characteristic size of $d \leq 1 \mu \mathrm{m}$ is significantly less than the diagonal length of the of the indenter diagonal, which is approximately $18 \mu \mathrm{m}$. Close values of microhardness are recorded in the presence of a large number of dark needle-like structures - whiskers, with a transverse size of a few microns, but a length of tens of micrometers. It can be seen from Fig. 8 a and Fig. 11b, that the whiskers are surrounded by a large number of small (about $1 \mu \mathrm{m}$ ) ceramic particles of various phases: $\mathrm{TiB}_{2}, \mathrm{TiB}, \mathrm{TiC}$. In this case the indenter also interacts with a heterogeneous structure that includes many hard ceramic particles situated in $\mathrm{a}-\mathrm{Ti}$ solid solution. The local maximum microhardness is close to the values obtained during the formation of the surfacing by continuous radiation 1413 HV0.3. (see fig. 8 [49])

In addition to the microhardness, the wear resistance of the formed composite material was measured. The study of wear resistance was carried out for three samples: Ti-6Al-4V and Ti-6Al-4V $-\mathrm{B}_{4} \mathrm{C}$ with a ratio of 9:1 wt\% obtained using PPR and continuous radiation. The experiment showed that in case of using continuous laser radiation a sample with a boron carbide content of $10 \mathrm{wt} \%$. has 4.2 times higher resistance to wear compared to the sample without ceramic. The use of PPR made it possible to significantly improve the characteristics of the deposited layer, which has a 6 times higher resistance to wear compared to the sample without ceramics.

\section{Discussion}


The TiB compound is recognized as one of the most beneficial reinforcing materials for titanium [8]. Composite metal-ceramic samples were prepared by in-situ synthesis using various mixtures of powders of $\mathrm{B}_{4} \mathrm{C}$ ceramics and Ti-6Al-4V alloy using layer-by-layer deposition of a mixture of powders and selective laser sintering.

It is known that boron carbide enters into a chemical reaction with titanium at high temperatures, as a result of which new chemical compounds $\left(\mathrm{TiB}, \mathrm{TiB}_{2}, \mathrm{TiC}\right)$ are formed $[19,25,28]$ :

$$
\begin{gathered}
5 \mathrm{Ti}^{+} \mathrm{B}_{4} \mathrm{C} \rightarrow 4 \mathrm{TiB}+\mathrm{TiC} \\
3 \mathrm{Ti}+\mathrm{B}_{4} \mathrm{C} \rightarrow 2 \mathrm{TiB}_{2}+\mathrm{TiC} \\
\mathrm{B}_{4} \mathrm{C} \rightarrow 4 \mathrm{~B}+\mathrm{C} \\
\mathrm{Ti}+\mathrm{TiB}_{2} \rightarrow 2 \mathrm{TiB}
\end{gathered}
$$

In work [19], changes in the standard Gibbs free energy of reactions (1) - (2) were calculated using thermodynamic data. In full accordance with previous studies [see. for example [18-22]], after laser melting of a mixture of $\mathrm{B}_{4} \mathrm{C}+\mathrm{Ti}-6 \mathrm{Al}-4 \mathrm{~V}$ powders, microstructural analysis based on SEM images clearly reveals the morphology of the phases being formed after solidification of the melt. Large (20-50 microns) fused particles of non-reactive ceramics $\mathrm{B}_{4} \mathrm{C}$ are observed (see Fig. 5,7,9). Dark-colored structures associated with $\mathrm{TiB}_{2}$ phases (Fig. 9 spectrum 4) are presented in the form of needles (whiskers) with characteristic dimensions: the diameter is 2-3 microns and the length is 30-50 microns (see fig. 7b, 8a). Note that such large TiB needles were studied in detail by Kooi et al [22]. Their complex structure and the presence of a hollow core filled, in particular, with titanium nuclei are shown. Previously conducted numerous studies [see. for example [23,24,28]], as well as our EDS analyzes (Fig. 7) shows that dark hexagonal prismatic or rectangular particles of $1 \mu \mathrm{m}$ in size formed by $\mathrm{TiB}_{2}$ phase. Light coloured round in shape structures (see Fig. 8) are the TiC phase. In addition to the clearly defined structures of the TiC and TiB phases, there is also a small amount of a metallic bond of the titanium alloy Ti-6Al-4V (see Fig. 8, spectrum 1 and 3). It is fundamentally important that all the products indicated in reactions (1 - 4) are observed using a transmission phase analysis by synchrotron radiation (see Fig. 11) and the total level of signal intensity from the signal of reflections of the created phases is of the order of or exceeds the reflection from the $\mathrm{a}-\mathrm{Ti}$ matrix, i.e. most of the titanium reacted with $\mathrm{B}_{4} \mathrm{C}$ to form various ceramic particles. The absence of the $B_{4} C$ reflection, i.e. a decrease in its level below the sensitivity level of the method and a low level of the aTi reflex completely correlates with the data of [28] for an initial $\mathrm{B}_{4} \mathrm{C}$ concentration of $20 \%$.

It should be noted that as a result of chemical action 1-4, not only a change in the chemical composition of the ceramics occurred, but also significantly smaller particles of $\mathrm{TiB}_{1} \mathrm{TiB}_{2}, \mathrm{TiC}$ ceramics were created. The initial boron carbide powder $B_{4} C$ had a splinter shape (Fig. 1a) with an average size of $d=40 \mu \mathrm{m}$. As a result of the reaction with titanium, a much larger number of ceramic particles of TiB and TiC phase were formed. These particles of 1-3 microns in size have a shape close to a cubic, and they are 
additionally connected by thin needles with characteristic dimensions of 2-3 microns in diameter and 3050 microns long.

It is shown that in the mechanism of the formation of the shape of a separate track and layer, the distribution and formation of ceramic particles, and the resistance to abrasive wear, an essential role was apparently played by the pulse-periodic mode of the supply of laser radiation energy.

Where: a $\sim 14.8 \mathrm{~mm}^{2} / \mathrm{s}$ is the thermal diffusivity of the deposited layer, $\mathrm{D} \sim 0.4 \mathrm{~mm}$ is the characteristic thickness of the deposited layer, $\mathrm{V}-16 \mathrm{~mm} / \mathrm{s}$ is the typical scanning speed. $\mathrm{W}=1 \mathrm{~kW}$ typical radiation power, $\mathrm{Cg} \sim 2 * 10^{6} \mathrm{~mm} / \mathrm{sec}-$ the speed of sound in the melt.

From the data presented in Table 2, it can be seen that the regime of quasi-stationary energy supply to the melt is realized, i.e. the time of temperature change is significantly longer than the interval between pulses $\left(T_{3} \gg T_{2}\right)$. However, the time of energy supply $T_{1}$ is short. Note that when using powerful pulses, the process of heating the metal is complicated. There is the direct effect of radiation on the substance, and the formation of plasma with the subsequent transfer of part of the energy from the plasma to the surface of the sample. Pulses of radiation and plasma act on the surface of the melt by pressure and heating of a narrow layer (absorption occurs in a narrow layer), generating heat and sound waves in it. It should be noted that the characteristic time of propagation of a sound wave over the molten pool $\mathrm{T}_{4}$ is short. So, during the energy release, the compression and then the rarefaction waves have time to act on the melt several times. Thus, the dynamic impact is limited by a time frame of the order of a pulse duration of about $1 \mu \mathrm{s}$. In a pulse-periodic mode, thermal processes can have a significantly stronger effect. During the time of the radiation pulse and the existence of the plasma, the surface of the melt heats up to very high temperatures, partial evaporation of the metal occurs, which leads to powerful temperature gradients, which can significantly exceed the values achieved when exposed to continuous radiation, both in the direction of the sample and along the radius. This is due to an increase in the acting radiation power in a pulse by more than 20 times. As a result, convective mass transfer, which plays an important role in the formation of the track shape and the distribution of ceramic particles over the volume as compared to diffusion, is significantly enhanced in the case of using PPR. One of the convection mechanisms is surface tension gradients. During laser heating the temperature of the material in the center of the beam is at its maximum and decreases towards the edges. The surface tension of a liquid (melt) depends on temperature and usually decreases with growth of temperature. As a result, a force arises on the surface, directed from the center of the light spot to its edges, and a fluid movement arises, leading to the formation, in the end, of a cylindrical concave meniscus.

Table 2. The characteristic times of the selective laser melting in a pulse-periodic mode. 
1 Energy absorption

2 Cooling time between pulses

3. Typical temperature change time

\begin{abstract}
4
The characteristic time of propagation of a sound wave in a molten bath

The number of impulses affecting the surface
\end{abstract}

$$
\mathrm{T}_{4}-\mathrm{D} / \mathrm{C}_{\mathrm{g}}
$$

Determined by the

characteristic radiation

time

$T_{2}=1 / f$

$\mathrm{T}_{3}=\mathrm{D}^{2} / \mathrm{a}$,

$N=f *(D / V)$

$Q=W \backslash f$

6 Pulse energy
$\mathrm{T}_{1}<1 \mu \mathrm{s}$.

$\mathrm{T}_{2}=16.6 \mu \mathrm{s}$

$\mathrm{T}_{3}=9.6 \mathrm{msec}$
$0.2 \mu \mathrm{s}$

$N=3700$ pcs.

It is this situation that was observed, as it can be seen in Figs 5 and 6 on the surface of the upper layer, at a high concentration of ceramics in the powder mixture $\left(\geq 6 \% \mathrm{~B}_{4} \mathrm{C}\right)$. With a decrease in the amount of ceramics, the surface becomes smooth. It should be noted that when using continuous radiation, the concave meniscus is formed only at a much higher ceramic concentration [49]. In turn, at a lower concentration of $\mathrm{B}_{4} \mathrm{C}$ and in its absence, the dependence of the tension coefficient on temperature reversed sign, which caused the formation of a convex cylindrical meniscus. At a concentration of $20 \%$ $\mathrm{B}_{4} \mathrm{C}+80 \% \mathrm{Ti}-6 \mathrm{Al}-4 \mathrm{~V}$, the meniscus surface was flat. It is important to note that the effect of dynamic and thermal waves and stronger temperature gradients are manifested not only in the change in the modes of formation of the track cross-sectional shape, but also in the distribution of ceramic particles. For example, most of the non-molten large $\mathrm{B}_{4} \mathrm{C}$ particles are localized in the region of the lateral edges of the tracks. As a result, a regular structure of the arrangement of large solid particles is formed, which is most clearly recorded at high concentrations of ceramics ( $\geq 10 \% \mathrm{~B}_{4} \mathrm{C}$ ) (see Figs. 5 and $6 \mathrm{a}$ ). When using continuous radiation, a completely different picture is observed, i.e. chaotic arrangement of particles of unmelted ceramic $\mathrm{B}_{4} \mathrm{C}$ (see Fig. $5 \mathrm{~b}$ ). In addition, the process of distribution of the phase composition and microstructure along the track height is realized, while not molten $\mathrm{B}_{4} \mathrm{C}$ particles are concentrated in the lower layer, see (see Fig. 7b).

When using PPR, such distribution is not observed (see Fig. 7a), the solid solution is homogeneous at the macrolevel, which is apparently due to periodic dynamic and thermal effects that cause mixing at the crystallization stage.

It is important to note that the crystallization process when using PPR has its own characteristics. Indeed, in the continuous mode of laser heating, the crystallization zone is separated from the area of radiation 
exposure, and the subsequent cooling of the melt is determined by the energy flow into the lower layers of the deposited sample. Therefore, solidification starts from the inner surface of the lower layer. It should be noted that after the deposition of each layer, the sample was cooled to a temperature of about $340 \mathrm{~K}$. Thus, the lower zone of the melt had a minimum temperature, and it is there that residual undissolved particles of the original $\mathrm{B}_{4} \mathrm{C}$ ceramic are recorded. The upper zone of the applied layer, which has the maximum temperature, is characterized by the formation of needles (whiskers). In [26,28], it is noted that after complete melting during solidification, different types of coating morphology are obtained from the molten pool, depending on the solidification rate. TiC solidifies first (melting point $3160^{\circ} \mathrm{C}$ ) and appears as a round particle shape or dendritic structure. Upon further cooling, the $\mathrm{TiB}_{2}$ melt (melting point 2970 ${ }^{\circ} \mathrm{C}$ ) begins to nucleate and solidifies in the form of a hexagonal or rhombohedral structure, which in our case fully corresponds to the formation of an intermediate zone with continuous laser radiation. It is this circumstance that apparently caused the separation in height within the melt layer by phases and microstructure when using continuous laser radiation to create a multilayer 3D sample [49].

When using PPR, the crystallization process is subjected to periodic dynamic and thermal effects, which can be caused by various mechanisms. For example, by the generation of an averaged flow in a viscous boundary layer near a crystallized material $[38,39]$ or due to the effect of low-amplitude vibrations on Marangoni convection [40]. In particular, in [40], from the analysis of various methods of metal modification, it was concluded that the methods of pulse-arc welding are superior.

A uniform distribution of the secondary phases of ceramic particles of $\mathrm{TiB}_{2}, \mathrm{TiB}, \mathrm{TiC}$, with a characteristic size of about 1-3 $\mu \mathrm{m}$ was obtained by in-situ synthesis using $\mathrm{Ti}$ and $\mathrm{B}_{4} \mathrm{C}$ in as starting powders and a repetitively pulsed supply of radiation energy at a frequency of $60 \mathrm{kHz}$. A more uniform distribution of secondary phases manifests itself in a smaller spread of microhardness when using PPR (see Fig. 13). This made it possible (with continuous irradiation and appropriate separation of phases and their localization in certain zones) to achieve, at the optimal track formation mode and the initial boron carbide concentration of $10 \mathrm{wt} \%$, the local maximum concentration of $\mathrm{TiB}_{2}, \mathrm{TiB}, \mathrm{TiC}$ microparticles in the $\mathrm{a}-\mathrm{Ti}$ solid solution and, accordingly, the maximum microhardness of the order of HVO.3 $=1419$.

On the other hand, when using the PPR for the first time for SLM, it was possible to achieve a 6 times higher value of resistance to wear compared to the sample without ceramics and 1.5 times higher than when using continuous laser radiation.

It should be noted that the local microhardness data and its fluctuations obtained by the selective laser melting (SLM) method using continuous radiation correlate well with the microhardness data obtained using an electric arc (TIG) at the same $\mathrm{B}_{4} \mathrm{C}$ concentration [28]. In this work, it was found that the range of hardness values for the $3 \mathrm{Ti}^{-} \mathrm{B}_{4} \mathrm{C}$ powder mixture is slightly higher $(712-891 \mathrm{HV} 0.05)$ than for the coating obtained with the $5 \mathrm{Ti}-\mathrm{B}_{4} \mathrm{C}$ powder mixture $(566-822 \mathrm{HV0.05})$, the average values of which are close to data in Fig. 13. 
For the $5 \mathrm{Ti}-\mathrm{B}_{4} \mathrm{C}$ concentration, the wear resistance compared to the sample without ceramics in [28] had a spread of $1.67-4.1$ times depending on the arc mode, which turned out to be close to our data using continuous radiation (4 times) and was also 1.5 times smaller compared with the use of PPR. Note that despite a decrease in the quality of the deposited layer at a high concentration of $3 \mathrm{Ti}-2 \mathrm{~B}_{4} \mathrm{C}$, microcrack pores, and wear resistance increase 11 times [28].

An increase in the relative resistance to wear with an increase in the initial concentration of $\mathrm{B}_{4} \mathrm{C}$ ceramics is due to an increase in the number of secondary phases, given their high hardness $\mathrm{TiB}_{2}(3500 \mathrm{HV} 0.05)$ and TiB (1900 HV0.05) [28]. These values indicate a tendency towards an increase in the microhardness value with an increase in the proportion of $\mathrm{B}_{4} \mathrm{C}$ in the powder mixture.

\section{Conclusion}

The paper studies the effect of repetitively pulsed radiation on the microstructure and mechanical properties of a metal matrix composite based on Ti-6Al-4V $+\mathrm{B}_{4} \mathrm{C}$ with different ceramic concentrations obtained by selective laser melting. As a result, the following conclusions can be drawn:

At a concentration of $B_{4} C$ ceramics of $10 \%$ of the mass. in the initial mixture, the deposited mass is homogeneous and has no cracks.

In the coating, most of the titanium reacted with $\mathrm{B}_{4} \mathrm{C}$ to form various ceramic particles $\mathrm{TiB}_{2}, \mathrm{TiB}, \mathrm{TiC}$.

It is shown that the use of repetitively pulsed radiation in selective laser melting makes it possible to improve the microstructure, obtain a more uniform distribution of the concentration of the secondary phases of ceramic particles $\mathrm{TiB}_{2}, \mathrm{TiB}, \mathrm{TiC}$, and increase the mechanical properties of metal matrix coatings in comparison with continuous radiation.

The maximum microhardness of the coating obtained with the use of PPR when using a mixture of Ti$6 \mathrm{Al}-4 \mathrm{~V}-\mathrm{B}_{4} \mathrm{C}$ with a ratio of $9: 1 \mathrm{wt} \%$ reaches the value $\mathrm{HV} 0.3=1419$.

The wear resistance of the metal-matrix coating obtained with PPR using a mixture of Ti-6Al$4 \mathrm{~V}-\mathrm{B}_{4} \mathrm{C}$ with a ratio of $9: 1 \mathrm{wt} \%$ is 6 times higher than that of a Ti-6Al-4V coating.

The wear resistance of a Ti-6Al-4V - $\mathrm{B}_{4} \mathrm{C}$ mixture with 9:1 $\mathrm{wt} \%$ metal obtained using repetitively pulsed radiation is 1.5 times greater than the same mixture obtained using continuous laser radiation.

\section{Declarations}

Funding: This study was funded by state assignment of Ministry of Science and Higher Education of the Russian Federation (project No. 121030900259-0).

Conflicts of interest/Competing interests: The authors declare they have no financial interests. 
Availability of data and material: This manuscript is a continuation of a series of works on the creation of a cermet composite based on boron carbide and titanium matrix using SLM.

Code availability: Not applicable

Ethics approval: The submitted work is original and dont published elsewhere in any form or language

Consent to participate: All authors give their consent

Consent for publication: All authors give their consent

\section{References}

[1] T. DebRoy, H.L. Wei, J.S. Zuback, T. Mukherjee, J.W. Elmer, J.O. Milewski, A.M. Beese, A. Wilson-Heid, A. De, W. Zhang, Additive manufacturing of metallic components - Process, structure and properties, Prog. Mater. Sci. 92 (2018) 112-224. https://doi.org/10.1016/j.pmatsci.2017.10.001.

[2] D.B. Miracle, Metal matrix composites - From science to technological significance, Compos. Sci. Technol. 65 (2005) 2526-2540. https://doi.org/10.1016/j.compscitech.2005.05.027.

[3] A. Aramian, S.M.J. Razavi, Z. Sadeghian, F. Berto, A review of additive manufacturing of cermets, Addit. Manuf. 33 (2020) 101130. https://doi.org/10.1016/j.addma.2020.101130.

[4] V.M. Fomin, A.A. Golyshev, V.F. Kosarev, A.G. Malikov, A.M. Orishich, N.S. Ryashin, A.A. Filippov, V.S. Shikalov, Creation of heterogeneous materials on the basis of B4C and Ni powders by the method of cold spraying with subsequent layer-by-layer laser treatment, J. Appl. Mech. Tech. Phys. 58 (2017) 947-955. https://doi.org/10.1134/S0021894417050224.

[5] P. Krakhmalev, I. Yadroitsev, Microstructure and properties of intermetallic composite coatings fabricated by selective laser melting of Ti-SiC powder mixtures, Intermetallics. 46 (2014) 147-155. https://doi.org/10.1016/j.intermet.2013.11.012.

[6] C. Hong, D. Gu, D. Dai, M. Alkhayat, W. Urban, P. Yuan, S. Cao, A. Gasser, A. Weisheit, I. Kelbassa, M. Zhong, R. Poprawe, Laser additive manufacturing of ultrafine TiC particle reinforced Inconel 625 based composite parts: Tailored microstructures and enhanced performance, Mater. Sci. Eng. A. 635 (2015) 118-128. https://doi.org/10.1016/j.msea.2015.03.043.

[7] S. Pouzet, P. Peyre, C. Gorny, O. Castelnau, T. Baudin, F. Brisset, C. Colin, P. Gadaud, Additive layer manufacturing of titanium matrix composites using the direct metal deposition laser process, Mater. Sci. Eng. A. 677 (2016) 171-181. https://doi.org/10.1016/J.MSEA.2016.09.002.

[8] C. Cai, B. Song, C. Qiu, L. Li, P. Xue, Q. Wei, J. Zhou, H. Nan, H. Chen, Y. Shi, Hot isostatic pressing of in-situ TiB/Ti-6Al-4V composites with novel reinforcement architecture, enhanced hardness and elevated 
tribological properties, J. Alloys Compd. 710 (2017) 364-374.

https://doi.org/10.1016/j.jallcom.2017.03.160.

[9] K.S. Ravi Chandran, K.B. Panda, S.S. Sahay, TiBw-reinforced Ti composites: Processing, properties, application prospects, and research needs, JOM. 56 (2004) 42-48. https://doi.org/10.1007/s11837-0040127-1.

[10] A.M. Vilardell, G. Fredriksson, I. Yadroitsev, P. Krakhmalev, Fracture mechanisms in the as-built and stress-relieved laser powder bed fusion Ti6Al4V ELI alloy, Opt. Laser Technol. 109 (2019) 608-615. https://doi.org/10.1016/j.optlastec.2018.08.042.

[11] M. Tang, L. Zhang, N. Zhang, Microstructural Evolution, Mechanical and Tribological Properties of TiC/Ti6Al4V Composites with Unique Microstructure Prepared by SLM, Mater. Sci. Eng. A. 814 (2021) 141187. https://doi.org/10.1016/j.msea.2021.141187.

[12] R. Chen, H. Fang, X. Chen, Y. Su, H. Ding, J. Guo, H. Fu, Formation of TiC/Ti 2 AlC and a $2+Y$ in insitu TiAl composites with different solidification paths, Intermetallics. 81 (2017) 9-15. https://doi.org/10.1016/j.intermet.2017.02.025.

[13] M. Yi, X. Zhang, G. Liu, B. Wang, H. Shao, G. Qiao, Comparative investigation on microstructures and mechanical properties of ( $\mathrm{TiB}+\mathrm{TiC}) / \mathrm{Ti}-6 \mathrm{Al}-4 \mathrm{~V}$ composites from Ti-B4C-C and Ti-TiB2-TiC systems, Mater. Charact. 140 (2018) 281-289. https://doi.org/10.1016/j.matchar.2018.04.010.

[14] T.W. Lee, C.H. Lee, Microstructure and mechanical properties of TiB2/TiAl composites produced by reactive sintering using a powder extrusion technique, J. Mater. Sci. Lett. 18 (1999) 801-803. https://doi.org/10.1023/A:1006645302032.

[15] S. Li, K. Kondoh, H. Imai, B. Chen, L. Jia, J. Umeda, Y. Fu, Strengthening behavior of in situ synthesized (TiC-TiB)/Ti composites by powder metallurgy and hot extrusion, Mater. Des. 95 (2016) 127-132. https://doi.org/10.1016/j.matdes.2016.01.092.

[16] S. Bhowmick, G. Sun, A.T. Alpas, Low friction behaviour of boron carbide coatings (B4C) sliding against Ti-6Al-4V, Surf. Coatings Technol. 308 (2016) 316-327.

https://doi.org/10.1016/j.surfcoat.2016.05.092.

[17] Y. Zhao, T. Yu, J. Sun, S. Jiang, Microstructure and properties of laser cladded B4C/TiC/Ni-based composite coating, Int. J. Refract. Met. Hard Mater. 86 (2020) 105112. https://doi.org/10.1016/j.jirmhm.2019.105112.

[18] B. Du, S.R. Paital, N.B. Dahotre, Phase constituents and microstructure of laser synthesized TiB2TiC reinforced composite coating on steel, Scr. Mater. 59 (2008) 1147-1150. https://doi.org/10.1016/j.scriptamat.2008.07.035. 
[19] J. Li, Z. Yu, H. Wang, M. Li, Microstructural characterization of titanium matrix composite coatings reinforced by in situ synthesized TiB + TiC fabricated on Ti6Al4V by laser cladding, Rare Met. 29 (2010) 465-472. https://doi.org/10.1007/s12598-010-0151-y.

[20] L.L. Bai, J. Li, J.L. Chen, R. Song, J.Z. Shao, C.C. Qu, Effect of the content of B4C on microstructural evolution and wear behaviors of the laser-clad coatings fabricated on Ti6Al4V, Opt. Laser Technol. 76 (2016) 33-45. https://doi.org/10.1016/j.optlastec.2015.07.010.

[21] J. Li, Z. Yu, H. Wang, M. Li, Microstructural evolution of titanium matrix composite coatings reinforced by in situ synthesized TiB and TiC by laser cladding, Int. J. Miner. Metall. Mater. 17 (2010) 481-488. https://doi.org/10.1007/s12613-010-0345-1.

[22] B.. Kooi, Y.. Pei, J.T.. De Hosson, The evolution of microstructure in a laser clad TiB-Ti composite coating, Acta Mater. 51 (2003) 831-845. https://doi.org/10.1016/S1359-6454(02)00475-5.

[23] M.S.K.K.Y. Nartu, S.A. Mantri, M. V. Pantawane, Y.-H. Ho, B. McWilliams, K. Cho, N.B. Dahotre, R. Banerjee, In situ reactions during direct laser deposition of Ti-B4C composites, Scr. Mater. 183 (2020) 2832. https://doi.org/10.1016/j.scriptamat.2020.03.021.

[24] M. Xia, A. Liu, Z. Hou, N. Li, Z. Chen, H. Ding, Microstructure growth behavior and its evolution mechanism during laser additive manufacture of in-situ reinforced ( $\mathrm{TiB}+\mathrm{TiC}) / \mathrm{Ti}$ composite, J. Alloys Compd. 728 (2017) 436-444. https://doi.org/10.1016/j.jallcom.2017.09.033.

[25] D. Tijo, M. Masanta, Mechanical performance of in-situ TiC-TiB2 composite coating deposited on Ti-6Al-4V alloy by powder suspension electro-discharge coating process, Surf. Coatings Technol. 328 (2017) 192-203. https://doi.org/10.1016/J.SURFCOAT.2017.08.048.

[26] D. Tijo, M. Masanta, A.K. Das, In-situ TiC-TiB2 coating on Ti-6Al-4V alloy by tungsten inert gas (TIG) cladding method: Part-I. Microstructure evolution, Surf. Coatings Technol. 344 (2018) 541-552. https://doi.org/10.1016/J.SURFCOAT.2018.03.082.

[27] Q. An, L. Huang, S. Jiang, X. Li, Y. Gao, Y. Liu, L. Geng, Microstructure evolution and mechanical properties of TIG cladded TiB reinforced composite coating on Ti-6Al-4V alloy, Vacuum. 145 (2017) 312319. https://doi.org/10.1016/J.VACUUM.2017.09.019.

[28] D. Tijo, M. Masanta, Effect of Ti/B4C ratio on the microstructure and mechanical characteristics of TIG cladded TiC-TiB2 coating on Ti-6Al-4V alloy, J. Mater. Process. Technol. 266 (2019) 184-197. https://doi.org/10.1016/j.jmatprotec.2018.11.005.

[29] J. Liu, Z. Liu, An experimental study on synthesizing TiC-TiB2-Ni composite coating using electrothermal explosion ultra-high speed spraying method, Mater. Lett. 64 (2010) 684-687. https://doi.org/10.1016/j.matlet.2009.12.038. 
[30] D. Ravnikar, N.B. Dahotre, J. Grum, Laser coating of aluminum alloy EN AW 6082-T651 with TiB2 and TiC: Microstructure and mechanical properties, Appl. Surf. Sci. 282 (2013) 914-922. https://doi.org/10.1016/j.apsusc.2013.06.089.

[31] Y. Diao, K. Zhang, Microstructure and corrosion resistance of TC2 Ti alloy by laser cladding with Ti/TiC/TiB 2 powders, Appl. Surf. Sci. 352 (2015) 163-168.

https://doi.org/10.1016/j.apsusc.2015.04.030.

[32] R. Wang, D. Gu, C. Chen, D. Dai, C. Ma, H. Zhang, Formation mechanisms of TiB2 tracks on Ti6Al4V alloy during selective laser melting of ceramic-metal multi-material, Powder Technol. 367 (2020) 597607. https://doi.org/10.1016/j.powtec.2020.04.027.

[33] Q.W. Meng, L. Geng, B.Y. Zhang, Laser cladding of Ni-base composite coatings onto Ti-6Al-4V substrates with pre-placed B4C + NiCrBSi powders, Surf. Coatings Technol. 200 (2006) 4923-4928. https://doi.org/10.1016/j.surfcoat.2005.04.059.

[34] Y. LEI, Z. WANG, X. CHEN, Effect of arc-ultrasound on microstructures and mechanical properties of plasma arc welded joints of SiCp/Al MMCs, Trans. Nonferrous Met. Soc. China. 21 (2011) 272-277. https://doi.org/10.1016/S1003-6326(11)60709-7.

[35] L. He, M. Wu, L. Li, H. Hao, Ultrasonic generation by exciting electric arc: A tool for grain refinement in welding process, Appl. Phys. Lett. 89 (2006) 131504. https://doi.org/10.1063/1.2357857.

[36] W.-L. Dai, Effects of high-intensity ultrasonic-wave emission on the weldability of aluminum alloy 7075-T6, Mater. Lett. 57 (2003) 2447-2454. https://doi.org/10.1016/S0167-577X(02)01262-4.

[37] L. Qingmei, Z. Yong, S. Yaoling, Q. Feipeng, Z. Qijie, Influence of ultrasonic vibration on mechanical properties and microstructure of 1Cr18Ni9Ti stainless steel, Mater. Des. 28 (2007) 1949-1952. https://doi.org/10.1016/j.matdes.2006.04.025.

[38] W. Wu, Influence of vibration frequency on solidification of weldments, Scr. Mater. 42 (2000) 661665. https://doi.org/10.1016/S1359-6462(99)00416-9.

[39] Z. Xu, J. Yan, G. Wu, X. Kong, S. Yang, Interface structure of ultrasonic vibration aided interaction between Zn-Al alloy and Al203p/6061Al composite, Compos. Sci. Technol. 65 (2005) 1959-1963. https://doi.org/10.1016/j.compscitech.2005.02.004.

[40] S. Kumar, C.S. Wu, G.K. Padhy, W. Ding, Application of ultrasonic vibrations in welding and metal processing: A status review, J. Manuf. Process. 26 (2017) 295-322. https://doi.org/10.1016/j.jmapro.2017.02.027.

[41] T. Chmielewski, D.A. Golański, New method of in-situ fabrication of protective coatings based on Fe-Al intermetallic compounds, Proc. Inst. Mech. Eng. Part B J. Eng. Manuf. 225 (2011) 611-616. https://doi.org/10.1177/2041297510394050. 
[42] J. Piekoszewski, A. Krajewski, F. Prokert, J. Senkara, J. Stanisławski, L. Waliś, Z. Werner, W. Włosiński, Brazing of alumina ceramics modified by pulsed plasma beams combined with arc PVD treatment, Vacuum. 70 (2003) 307-312. https://doi.org/10.1016/S0042-207X(02)00660-7.

[43] G.Z. (Grigoriī Z. Gershuni, D.V. (Dmitrï V. Li囚u囚bimov, Thermal vibrational convection, John Wiley \& Sons, 1998.

[44] M. Kawaji, R.Q. Liang, M. Nasr-Esfahany, S. Simic-Stefani, S. Yoda, The effect of small vibrations on Marangoni convection and the free surface of a liquid bridge, Acta Astronaut. 58 (2006) 622-632. https://doi.org/10.1016/j.actaastro.2006.03.002.

[45] S. Yang, R. Liang, F. Yan, T. Gao, Y. Feng, Thermocapillary Convection and Surface Fluctuation in a Liquid Bridge under Lateral Vibrations, Microgravity Sci. Technol. 27 (2015) 1-10. https://doi.org/10.1007/s12217-014-9407-8.

[46] A.N. Malov, A.M. Orishich, Ultimate energy characteristics of a mechanically Q-switched CO2 LASER, Tech. Phys. Lett. 40 (2014) 170-173. https://doi.org/10.1134/S1063785014020242.

[47] A.A. Golyshev, A.M. Orishich, A.A. Filippov, Similarity Laws in Laser Cladding of Cermet Coatings, J. Appl. Mech. Tech. Phys. 60 (2019) 758-767. https://doi.org/10.1134/S0021894419040217.

[48] A.I. Ancharov, A.Y. Manakov, N.A. Mezentsev, B.P. Tolochko, M.A. Sheromov, V.M. Tsukanov, New station at the 4th beamline of the VEPP-3 storage ring, Nucl. Instruments Methods Phys. Res. Sect. A Accel. Spectrometers, Detect. Assoc. Equip. 470 (2001) 80-83. https://doi.org/10.1016/S01689002(01)01029-4.

[49] A. Golyshev, A. Orishich, Microstructure and mechanical characterization of TI6AL4V-B4C metal ceramic alloy, produced by laser powder-bed fusion additive manufacturing, Int. J. Adv. Manuf. Technol. 109 (2020) 579-588. https://doi.org/10.1007/s00170-020-05509-1.

\section{Figures}




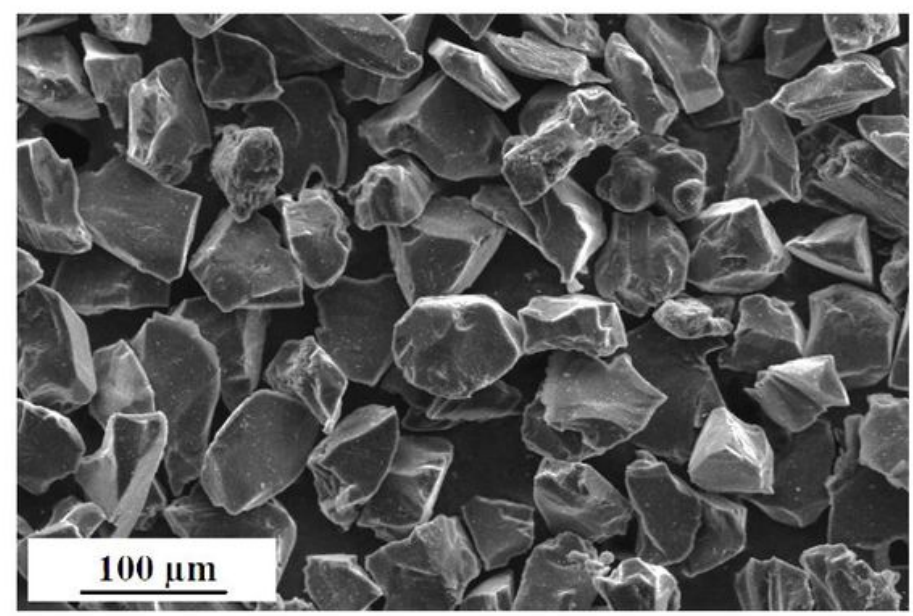

a)

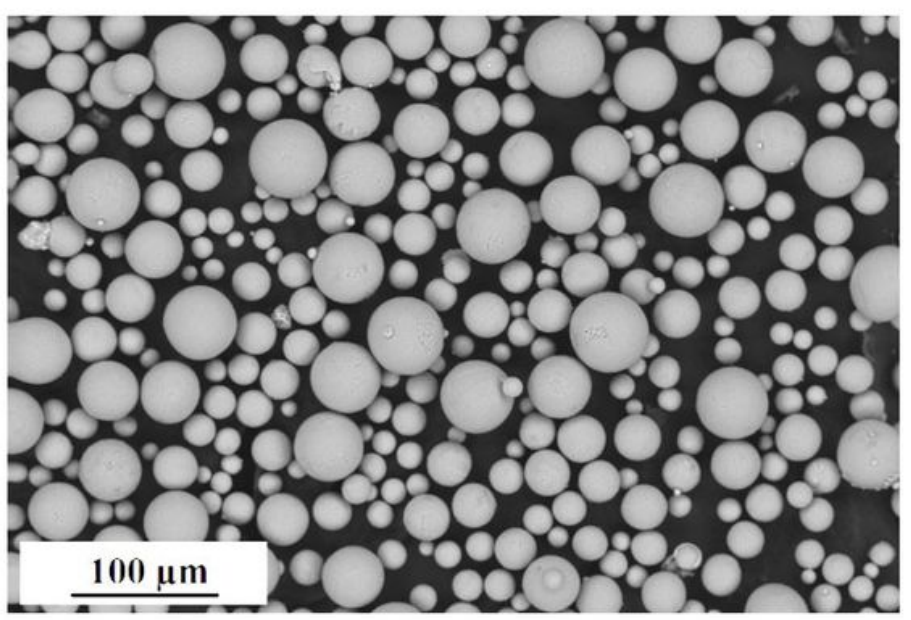

b)

Figure 1

Electron microscope image of the powders used: a - B4C, b- Ti-6Al-4V

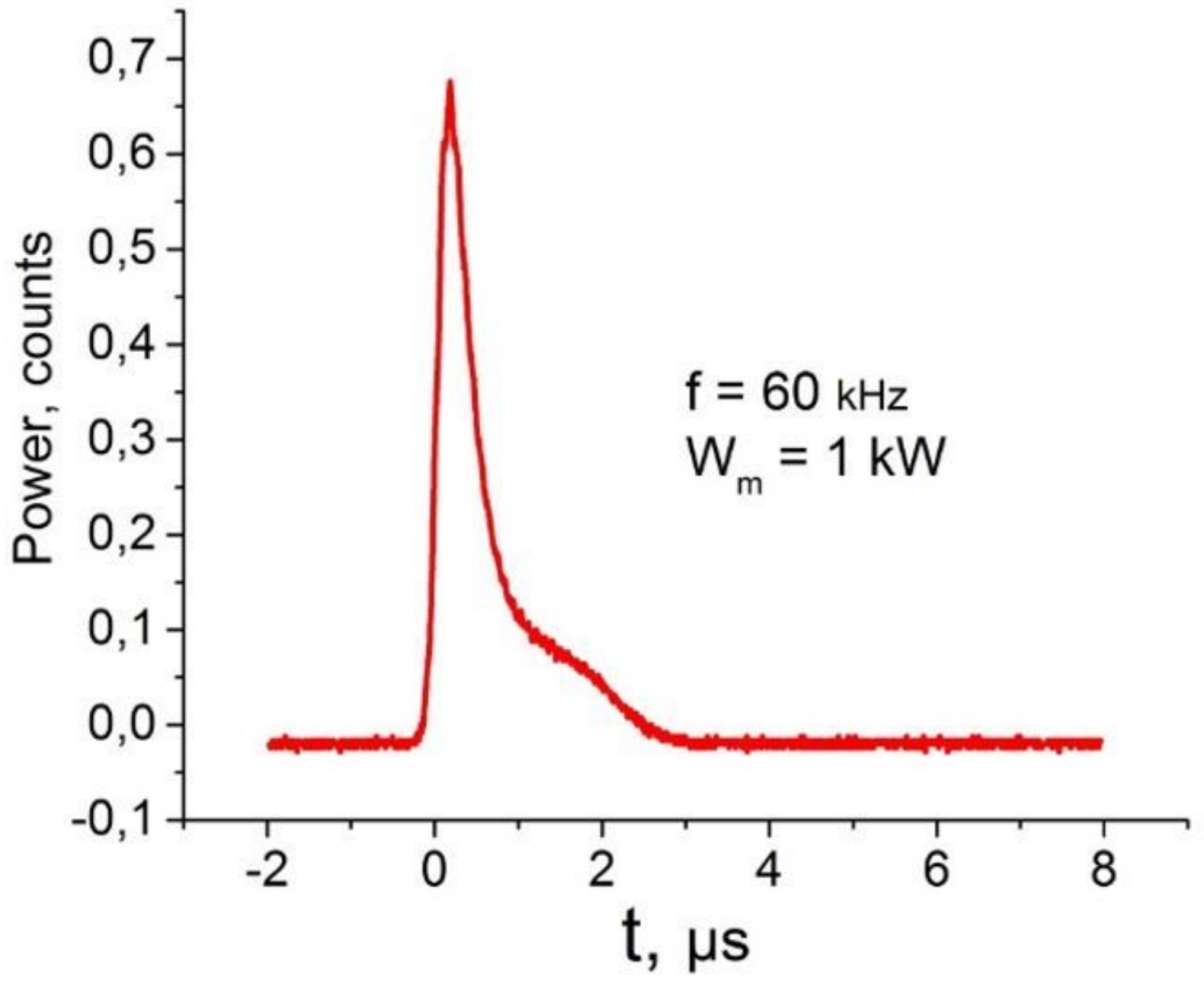

Figure 2 
The oscillogram of the radiation pulse.

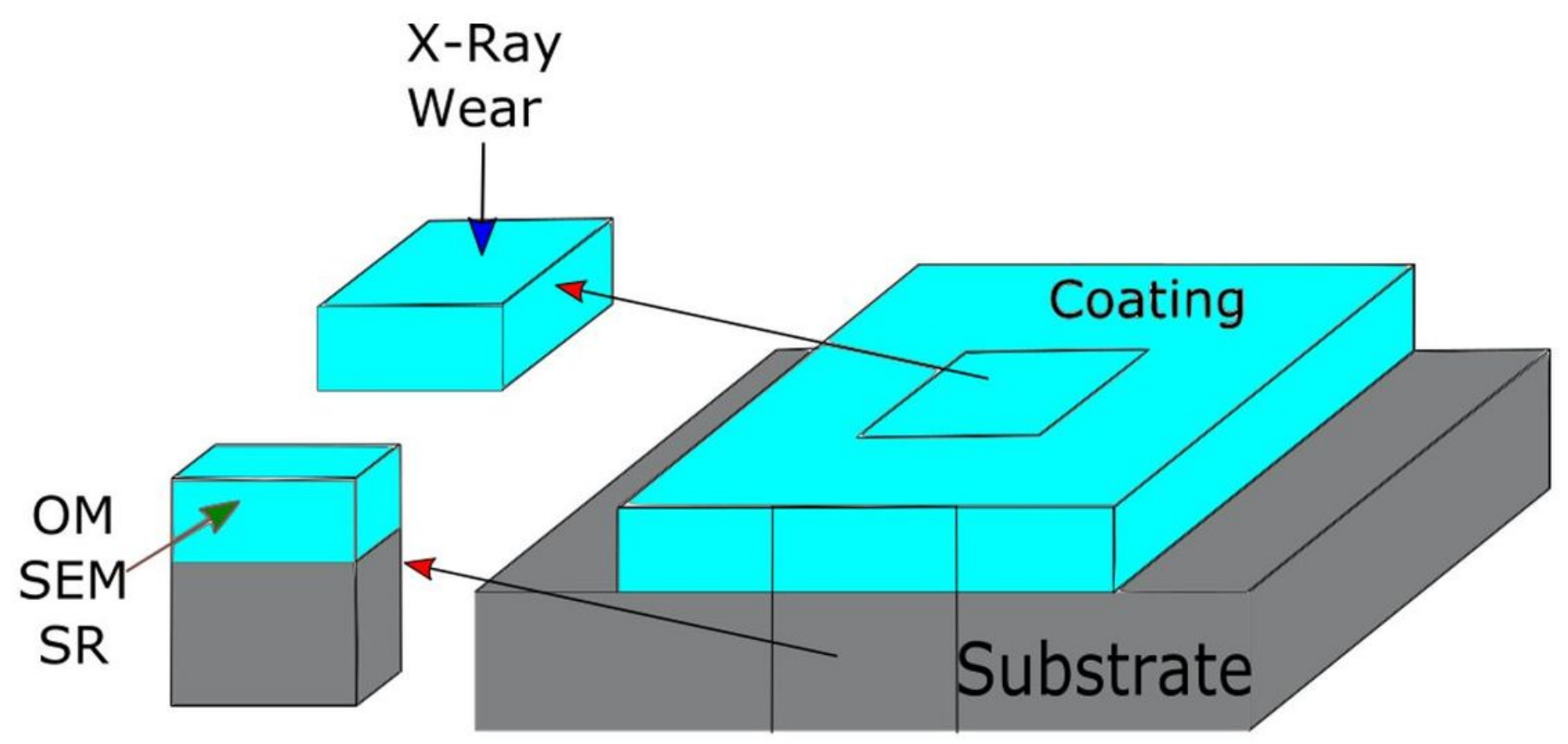

Figure 3

Metallographic studies scheme. 


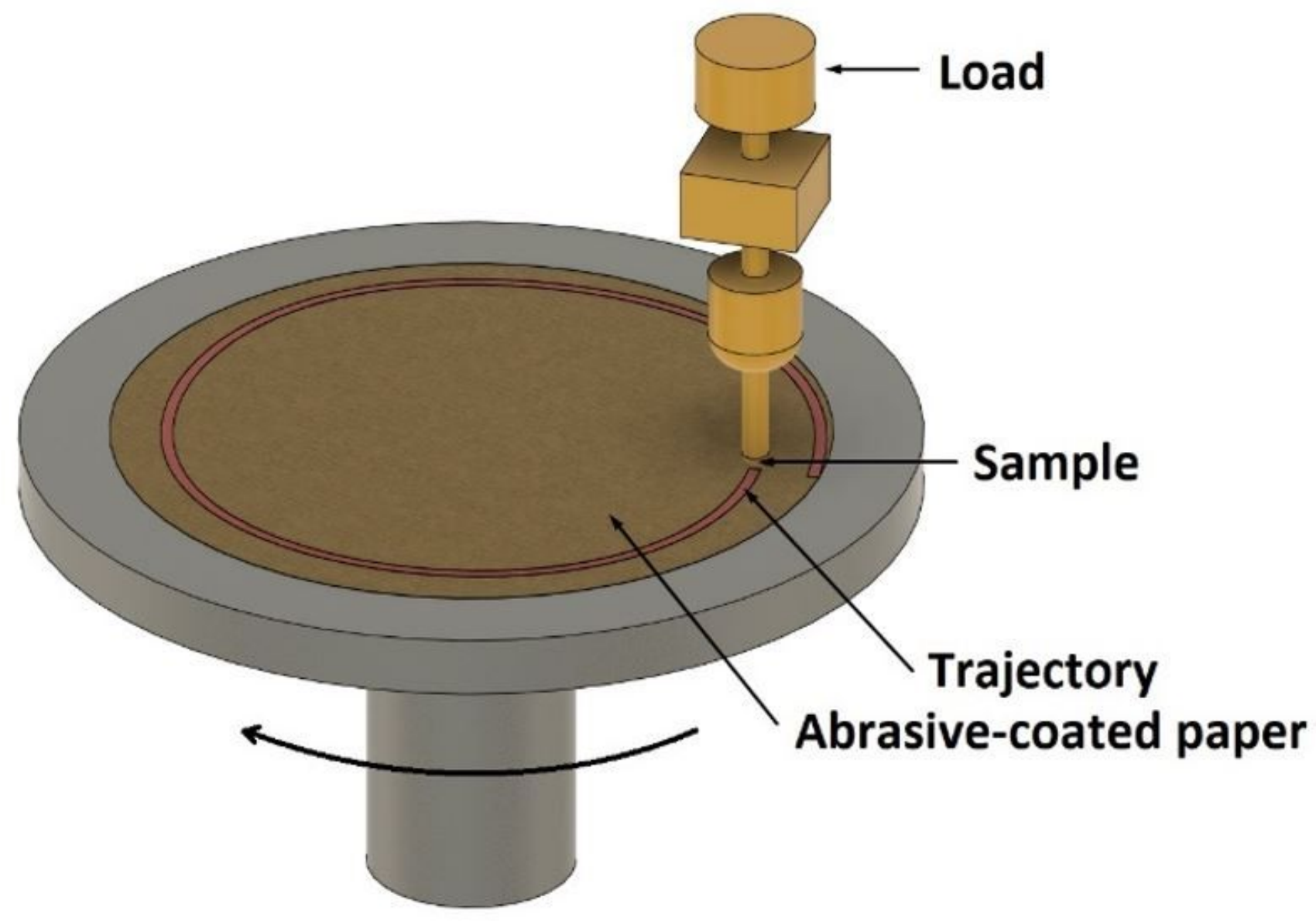

Figure 4

Scheme of a device for assessing wear resistance. 


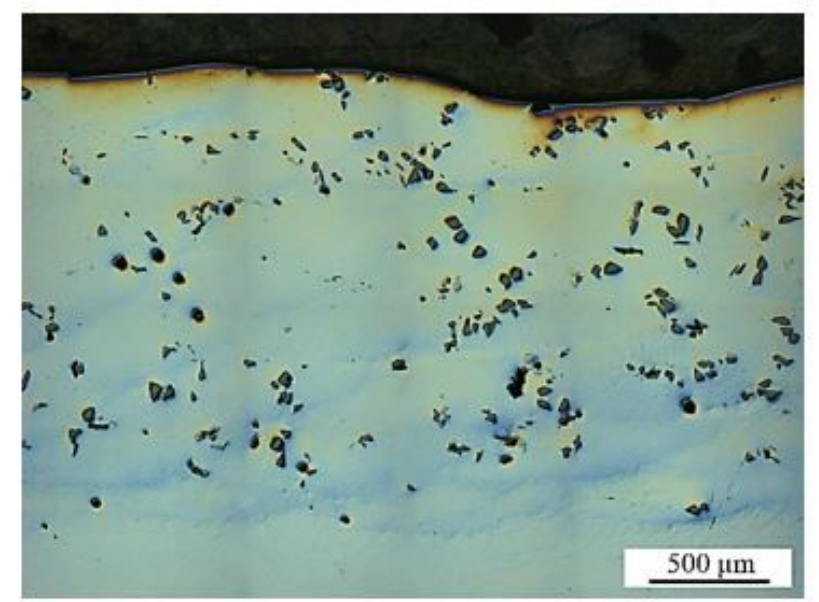

a

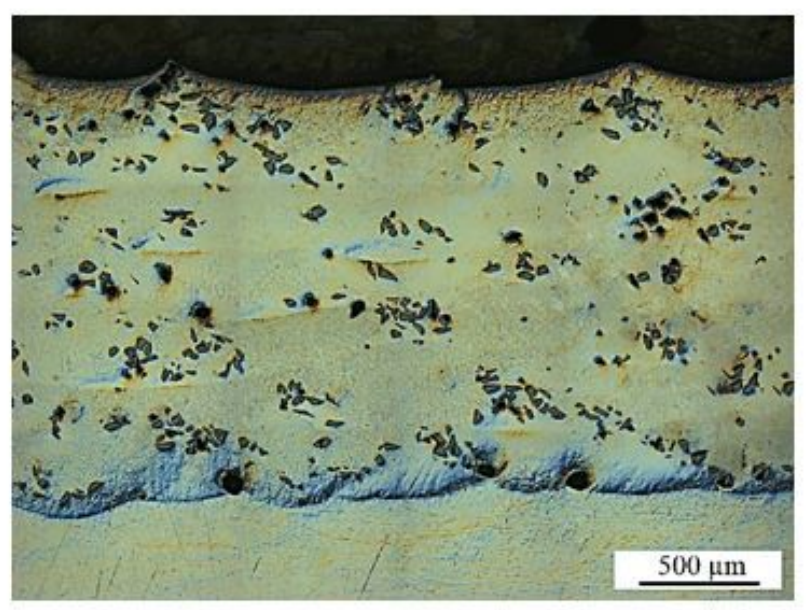

$\mathrm{b}$

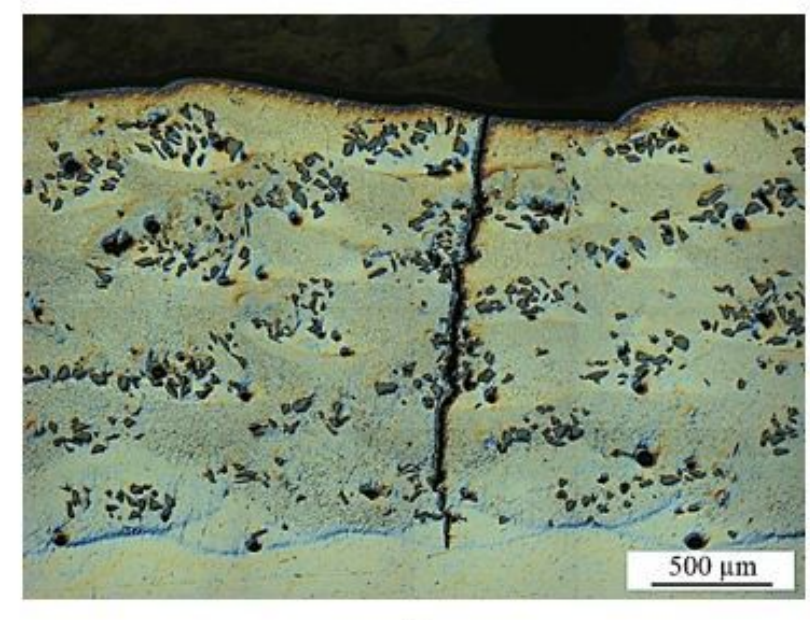

c

\section{Figure 5}

Optical image of cross-sections of 3D arrays with different concentrations of ceramics Ti-6Al-4V - B4C (a - 4 \% wt. B4C, b - $10 \%$ wt. B4C, c - $15 \%$ wt. B4C) 


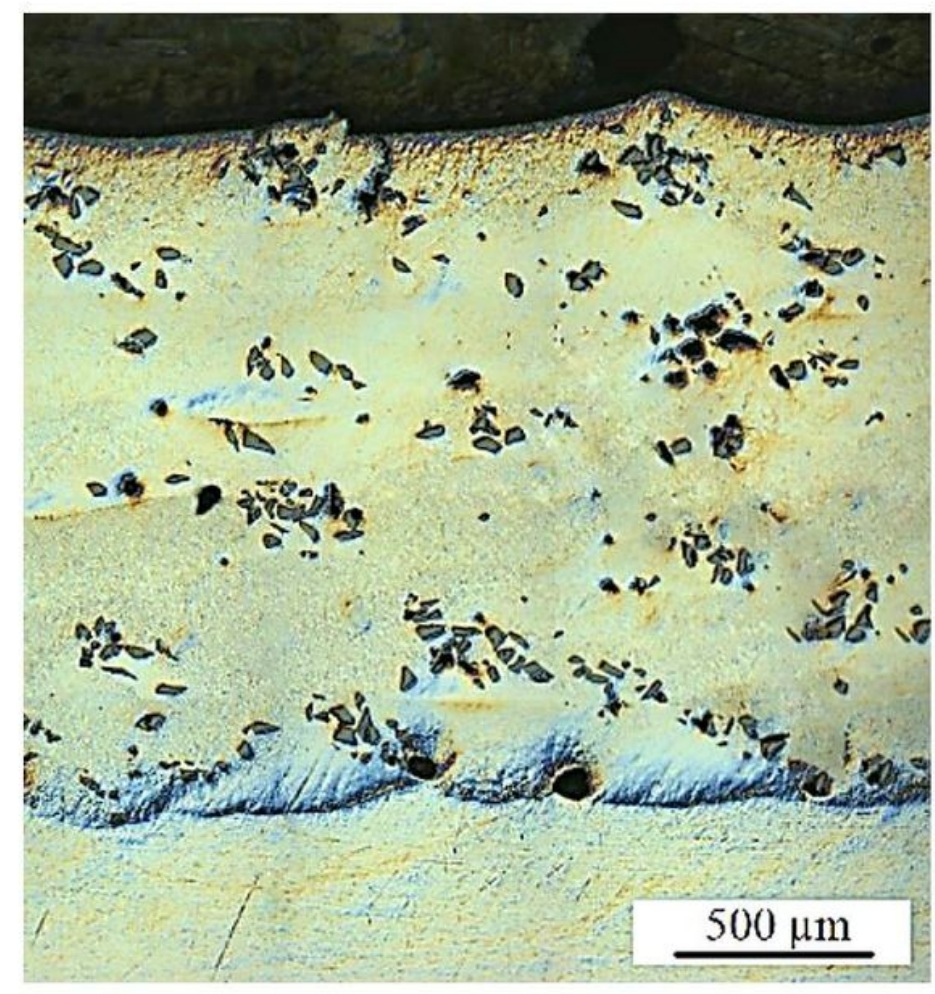

$\mathrm{a}$

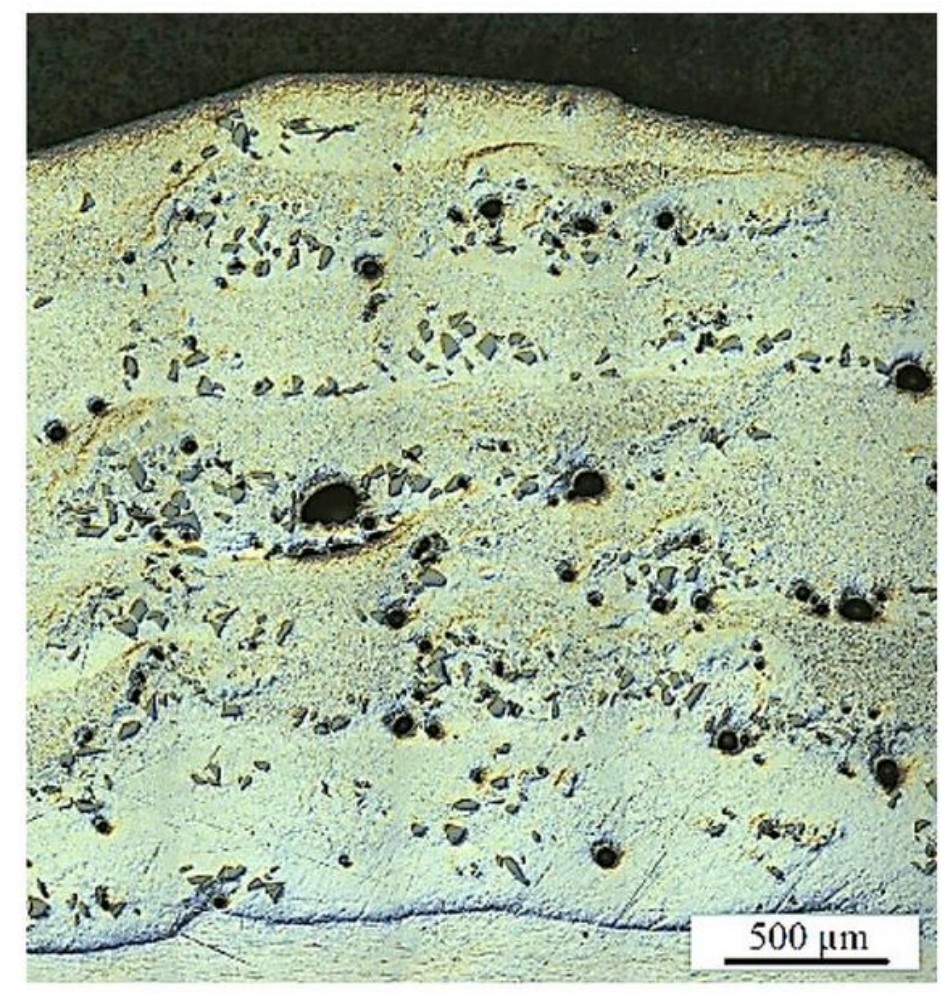

b

\section{Figure 6}

Optical image of cross-sections of 3D arrays obtained using pulse-periodic (a) and continuous radiation (b) at a ceramic concentration of $10 \mathrm{wt} \%$ 


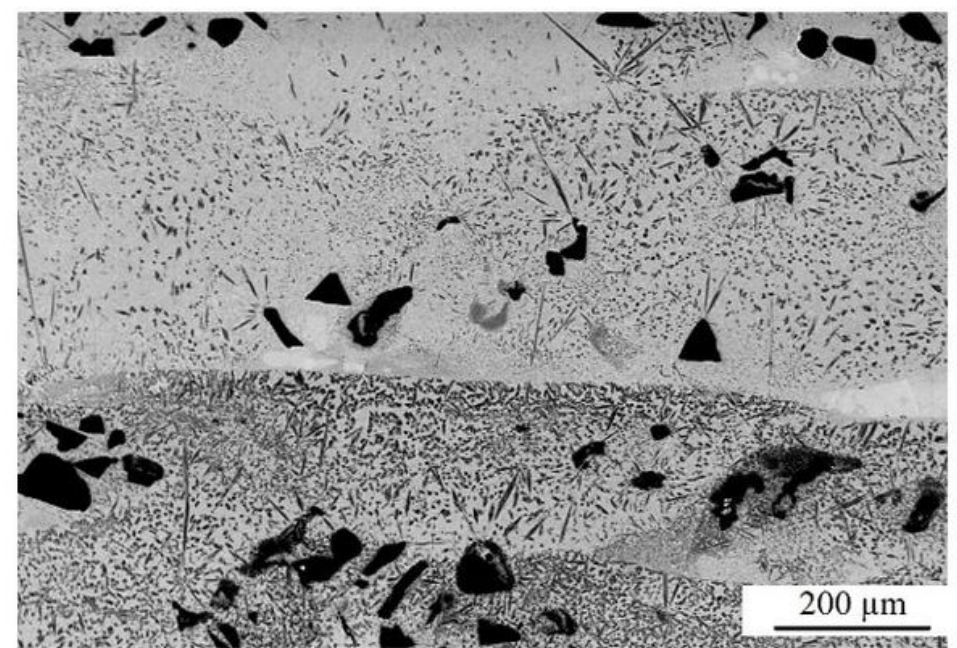

a

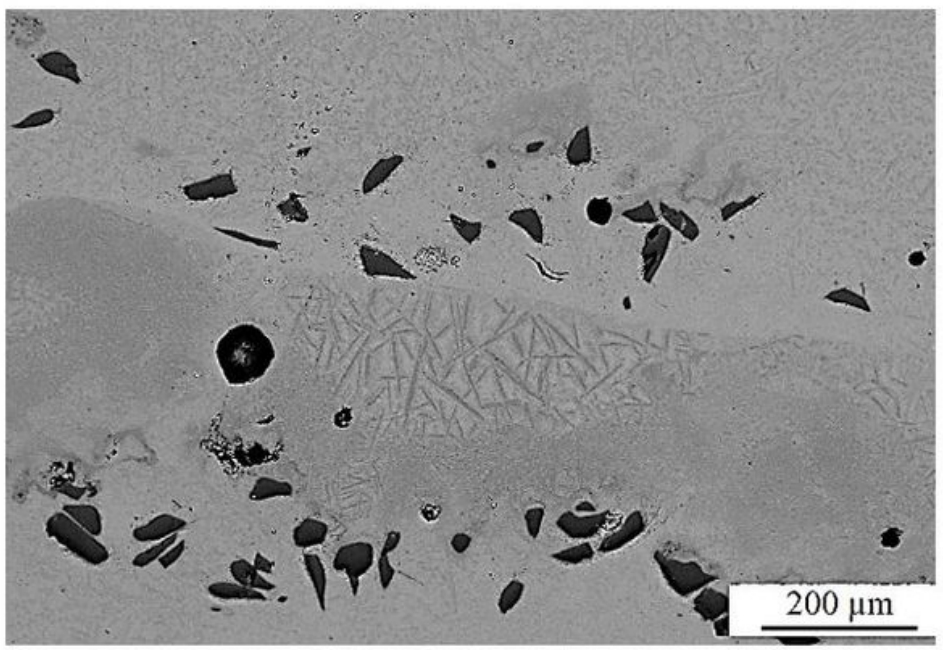

c

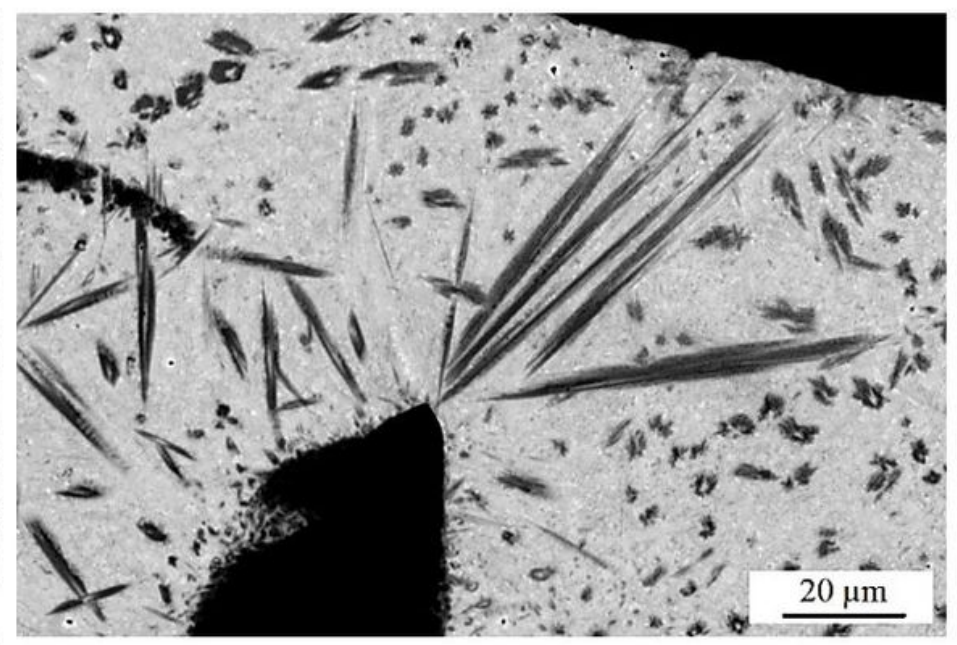

b

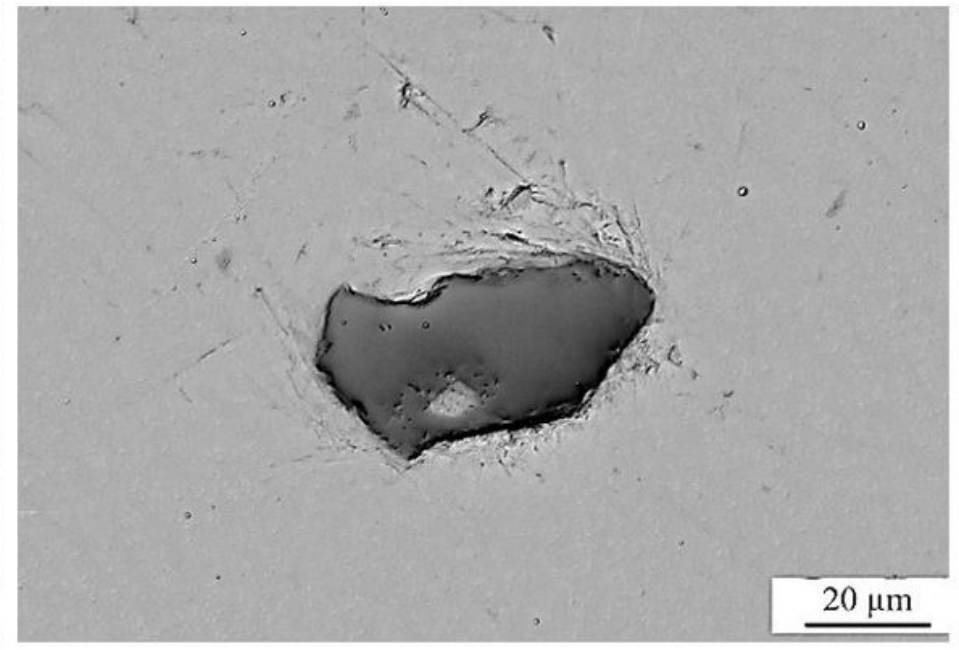

$\mathrm{d}$

Figure 7

EDX image of the microstructure of the Ti-6Al-4V - B4C samples with a ratio of 9:1 wt\%. (a, b - pulseperiodic radiation; $\mathrm{c}, \mathrm{d}$ - continuous radiation)

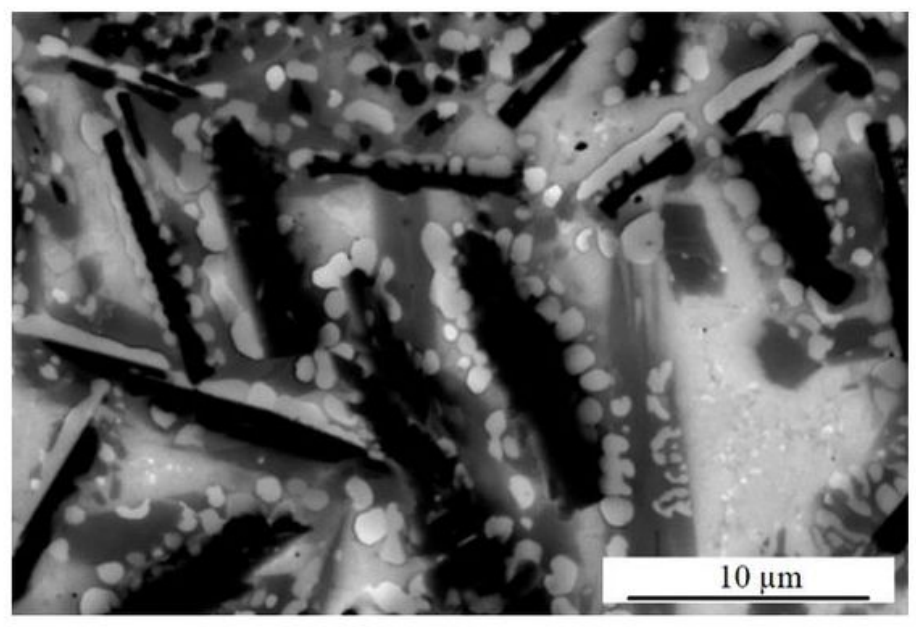

a

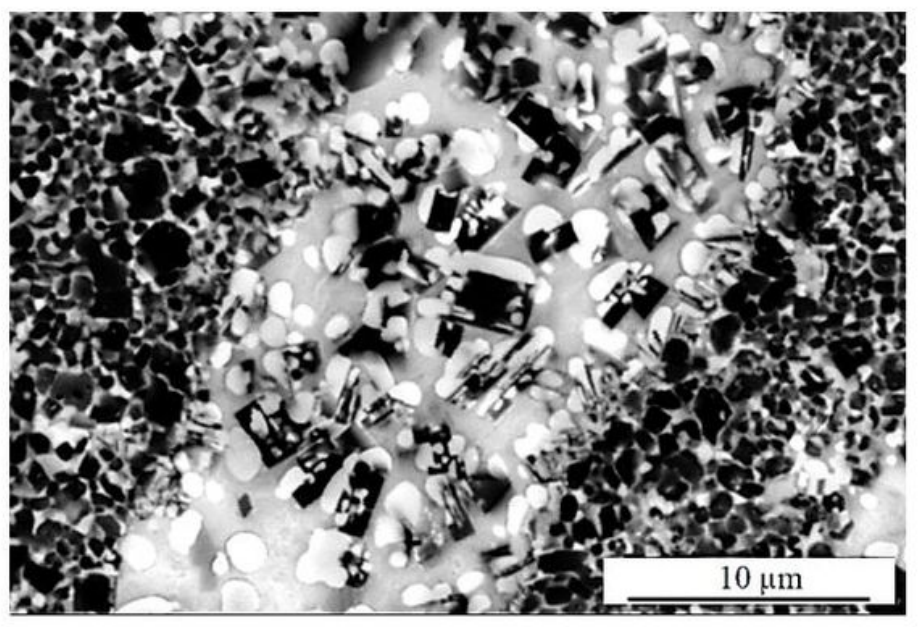

b 
Figure 8

EDX image of the microstructure of a Ti-6Al-4V - B4C sample with a ratio of 9: $1 \mathrm{wt} \%$

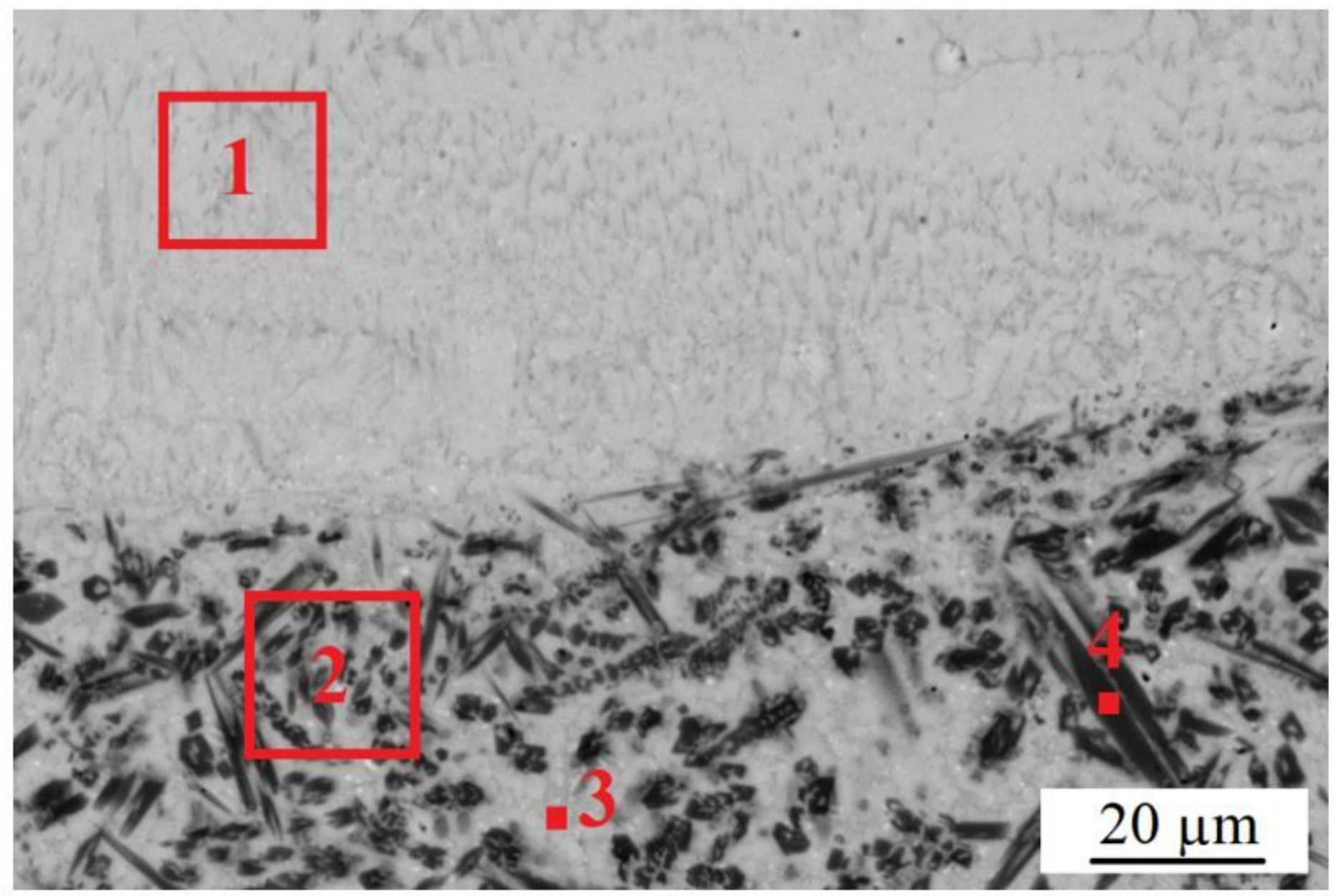

\section{Figure 9}

EDX image and places of measurement of the elemental composition of the Ti-6Al-4V - B4C array with a ratio of $94: 6 \%$ wt. 


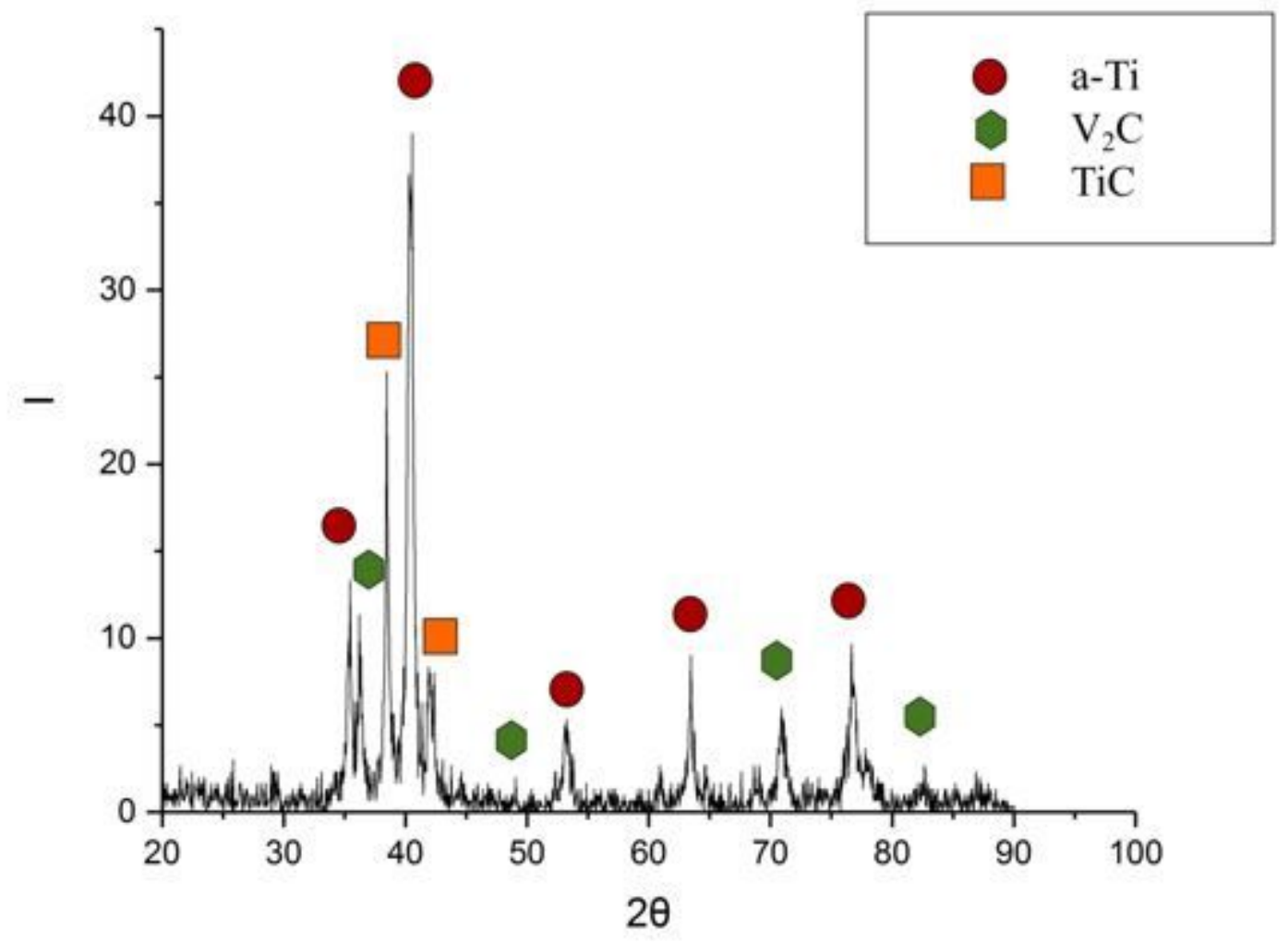

Figure 10

X-ray diffraction patterns of the cross-section of the sample Ti-6Al-4V - B4C with a ratio of 9: $1 \mathrm{wt} \%$ 


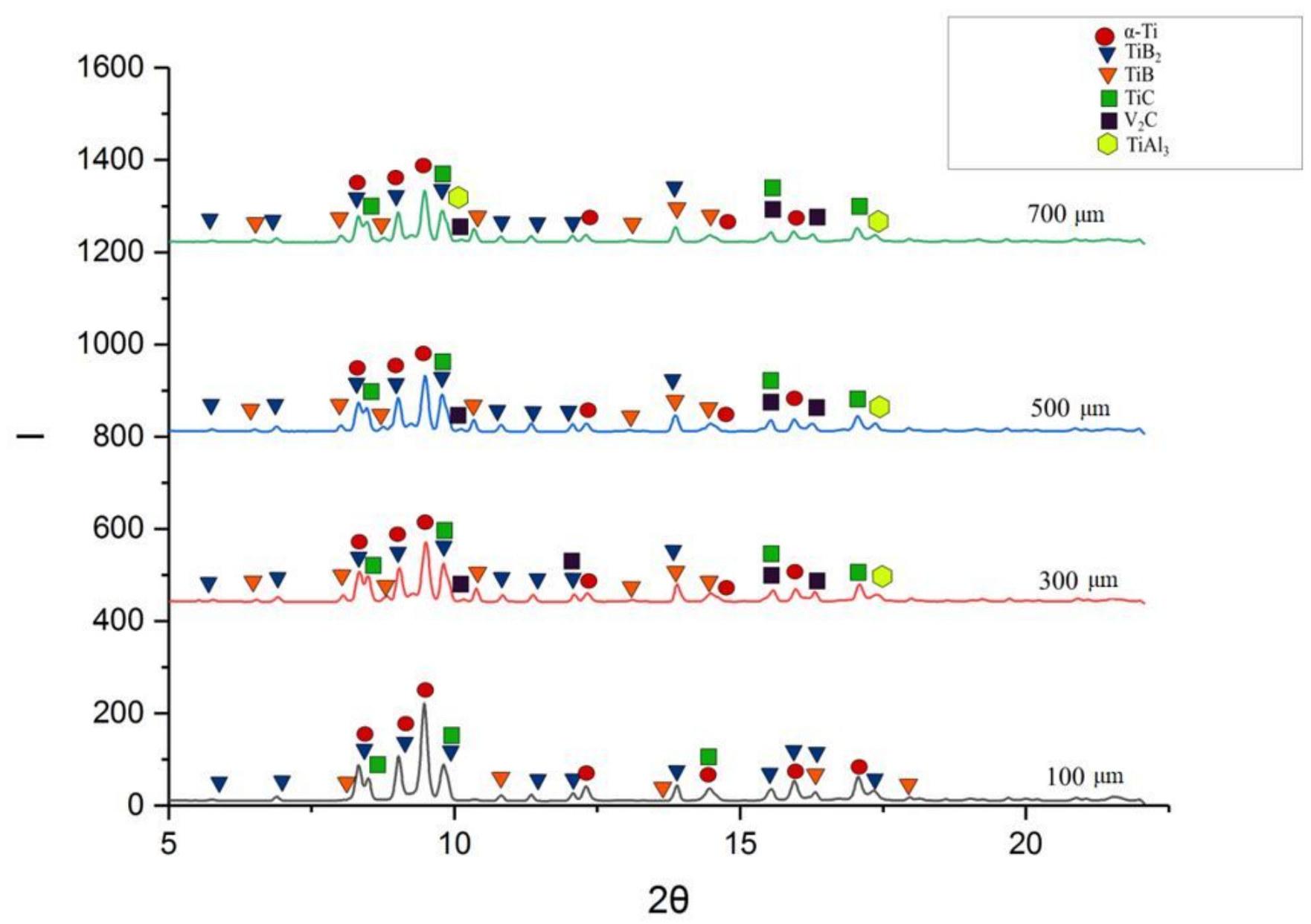

Figure 11

X-ray diffraction patterns of the cross-section of the sample with cladded Ti-6Al-4V - B4C with a ratio of 9: $1 \%$ wt. Distance is indicated from the top surface. 


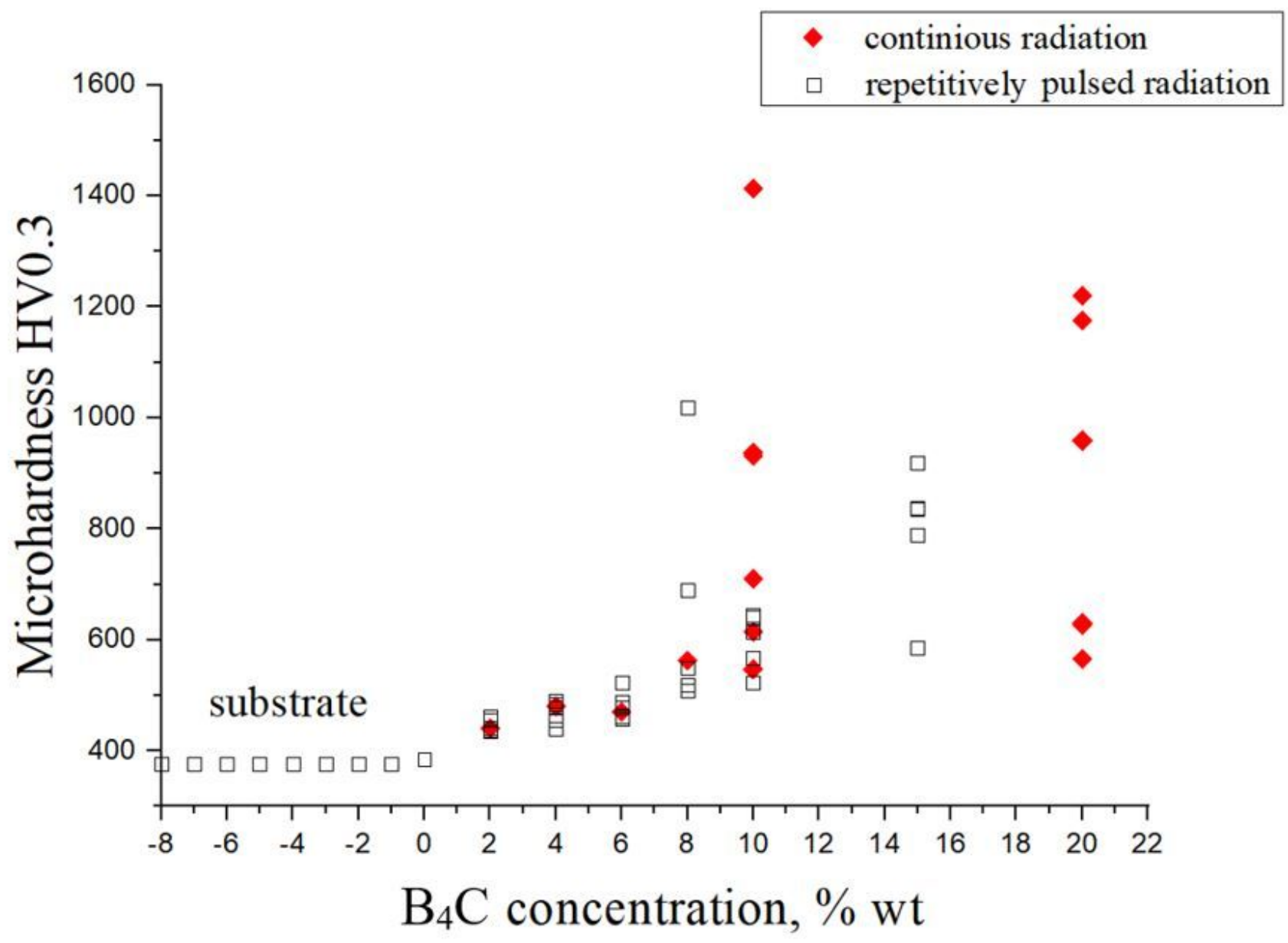

Figure 12

The value of the microhardness of multilayer deposited structures depending on the concentration of ceramics in the initial powder mixture

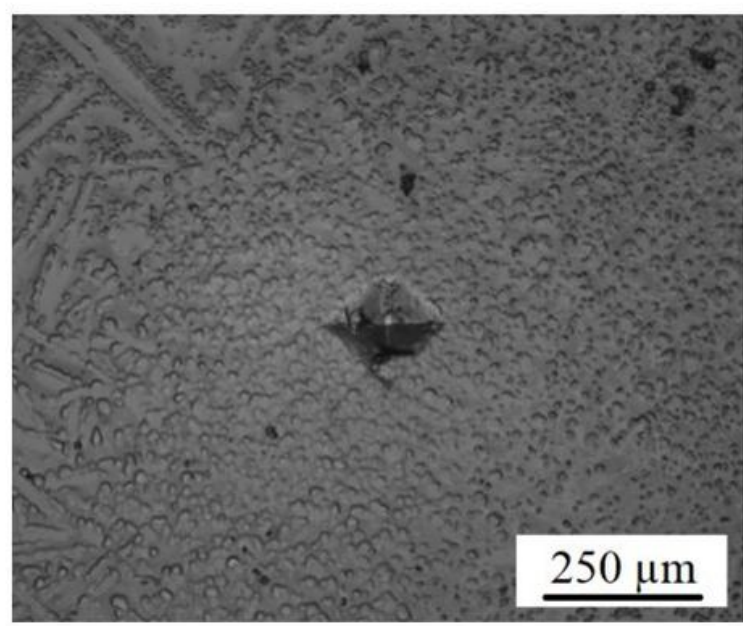

a

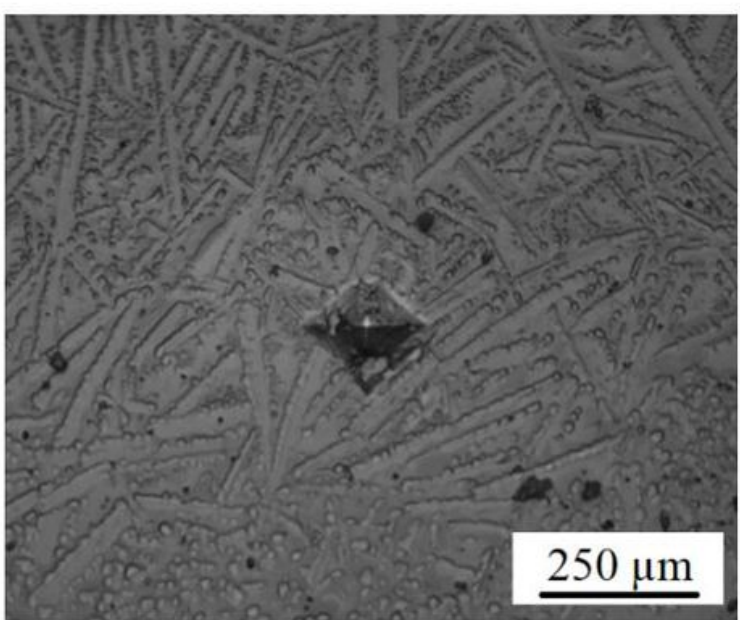

b

Figure 13 
Images of a sample with overlaying Ti-6Al-4V - B4C with a ratio of 9: $1 \mathrm{wt} \%$ obtained by continuous radiation with indentations from an indenter in different zones with a maximum microhardness value. a) Zone with submicron particles, HV0.3 $=1419$, b) zone with whiskers and submicron particles HV0.3 = 1335 